\title{
Analytical modeling of exit Burr in drilling of Ti6Al4V alloy
}

\author{
ANKIT RANA $^{1}$, GANESH DONGRE ${ }^{2}$ and SUHAS S JOSHI ${ }^{1, *}$ \\ ${ }^{1}$ Department of Mechanical Engineering, Indian Institute of Technology Bombay, Powai, Mumbai 400076 , \\ India \\ ${ }^{2}$ Industrial and Production Engineering Department, Vishwakarma Institute of Technology, Pune 411037, India \\ e-mail: ssjoshi@iitb.ac.in
}

MS received 7 October 2018; accepted 22 March 2019; published online 6 May 2019

\begin{abstract}
Burrs affect precision components and cause assembly related problems, and in general, decrease manufacturing productivity. Drilling burr formation involves multiple stages that are influenced by variation in thrust forces, temperature, stress conditions, and deformation modes in the unsupported length of the workmaterial below the drill. Several of these have not been adequately investigated so far. Therefore, the objective of this work is to model the complex phenomena that occur just before the exit of the drill tip from the bottom surface of the hole, and up to the complete exit of the drill point from the work surface. Accordingly, two models have been developed: (i) to estimate onset of bending in conjunction with theory of plasticity, which leads to the formation of a small drill cap under the pressure of steady-state drilling thrust forces, and (ii) to evaluate exit burr size that involves stretching and bending of a thin layer below the drill tip, using the principle of energy conservation. It is observed that a fracture is initiated at the chisel edge corner resulting in the formation of a small drill cap. The exit burr size predicted by the model is within one standard deviation from the average burr height as determined from the experimental data.
\end{abstract}

Keywords. Burr formation; exit Burr; thrust force; temperature; drill cap.

\section{Introduction}

Drilling involves severe deformation of material with high stresses and strains, which leads to high forces and large heat accumulation near cutting edges. This also causes formation of entry and exit burrs, requiring expensive deburring to meet part assembly specifications. Any reduction in de-burring could lead to a significant reduction in overall manufacturing cost. Drilling burr formation is a complex phenomenon involving multiple stages and elastic-plastic bending and fracture of drill caps. Several researchers have performed experiments as well as formulated mathematical models of burr formation during drilling as summarized below.

Gillipse [1] modelled burr formation by considering lateral flow of material along with bending of the material around some fixed pivot point around the edge of the hole. Ko and Lee [2] modelled burr as a function of distance of axis of drill from periphery of the hole. As the drill advances, a fracture occurs either at the tip of the drill or at the periphery of the hole depending on the stress condition. In another approach, Sofronas [3] used principle of energy balance, in drilling to find the point at which the downward cutting force of the drill is equivalent to the force required

*For correspondence to plastically deform the remaining material underneath the drill into a burr. On the other hand, Jinsoo and Dornfeld [4] used energy balance equation just before the drill tip exits from the bottom surface of the plate being drilled to find the burr initiation point. They found that this approach is more appropriate for ductile work materials. Niknam and Songmene [5] presented an analytical model to predict burr thickness, on the exit side during slot/up milling operation of ductile materials. Their model considers geometry of burr formation and the principle of continuity of work at the transition from chip formation to burr formation. Ravi et al [6] developed a model of burr formation using geometry of burr formation and principle of continuity of work at the transition from chip formation to burr formation. They noted that that burr height prediction in micro-end milling is challenging due to the complex geometry of material removal and micro-structural effects encountered during cutting at that length scales. Weng and Tang [7] presented a coupled thermo-mechanical model of plane-strain orthogonal metal cutting including burr formation is presented wherein Normalized Cockroft-Latham damage criterion was used to characterize the burrs quantitatively near the exit of orthogonal cutting. Matsumura and Leopold [8] presented a minimum cutting energy model, wherein minimum thrust force with radial chip flow direction has been suggested to reduce the burr formation. Normally, 
application of vibrations is found to reduce burr formation in drilling. In this regard, Cheng and Bone [9] developed a numerical model, adopted from Jinsoo and Dornfeld's energy balance, to incorporate variation in thrust forces and elastic-plastic deformation of the uncut material to form a burr. In the analytical model by Stéphane et al [10], burr is assumed to be formed as a result of plastic deformation of the work-material below the drill without any fracture using the theory of slip planes. In the above models, geometry of material deformation has been used to predict burr formation. On the other hand, Saunder and Mauch [11] divided the burr formation process under the action of thrust forces to involve indentation under the drill point, orthogonal cutting by the chisel edge and oblique cutting by the cutting lips of the drill. They predicted initiation of the first fracture near the axis of the drill, followed by the second fracture at the drill periphery. The uncut material was considered to transform into a burr. Based on the model by Saunders and Mauch [11], a combined experimental and statistical analysis by Lauderbaug [12] suggested that significant parameters influencing burr size are feed rate, ratio of chisel edge diameter to drill diameter, drill diameter, point angle and yield strength along with some second order interactions among these parameters. Abdelhafeez et al in their paper described experimental analysis of drilling titanium and aluminium alloys using diamond coated drills. They have analysed effect of cutting speed and feed rate on burr formation [13]. Mondal et al described use of artificial neural network (ANN) optimisation method for modelling of drilling burr formation on low alloy steel [14]. A paper on investigation of drill geometry and pilot holes on thrust force and burr height has been analysed by Rezende et al and they have concluded that tool and cutting speed are most significant parameters for thrust force and tool and feed rate are most important parameters for burr formation [15]. Deger et al in their paper on effect of cutting parameters on hole quality and burr height used CFRP as work material and they have given optimum processing conditions specific to stacking configuration [16]. Kundu et al studied the effect of exit edge bevelling on burr height while drilling aluminium alloy. According to their study optimum burr height is observed at bevel angle of $150^{\circ}$, cutting velocity of $20 \mathrm{~m} / \mathrm{min}$ and feed rate of $0.032 \mathrm{~mm} / \mathrm{rev}$ [17].

It is apparent from the above discussion that modelling of burr formation in drilling has evolved from simple geometrical models, to those involving physical phenomena such as drill cap formation, fracture at the periphery of the hole, bending of the unsupported part of the work-material under the drill, and plastic deformation of the uncut part of the work-material as the drill exits the hole surface. It is understood that material deformation during various stages of burr formation is significantly influenced by variation in thrust forces, temperature, stress conditions, and deformation modes in the unsupported length of the work-piece below the drill as the drill begins to exit the work surface, which hitherto have not been paid adequate attention to. Therefore, specific objective of this work is to develop a model of burr formation mechanism considering various physical phenomena that are typically involved such as protrusion of the material at the center, formation of crack near the chisel edge corner to form a small drill cap, and finally deformation of the uncut material to form the exit burr. The Ti alloy, is commonly used metallic alloy in the aerospace industries and it is used as work material for this study. The machining of titanium alloys is difficult because it will have a high yield stress to tensile strength ratio and the flow stress increases dramatically with strain rate. The high temperature strength, very low thermal conductivity, relatively low modulus of elasticity, high strain hardening, poor dislocation motion and high chemical reactivity makes this material difficult to machine as compared to other conventional materials. The work has been organized in five different sections as described below.

\section{Physics based approach to burr formation model}

Various physical phenomena observed in drilling of titanium alloy including the formation of a burr are correlated with the variation in thrust forces, as shown in figure 1(a). As the drill enters the work-piece, the thrust force increases and reaches a steady-state, see region $(A)$ in figure 1(a). As drilling progresses, thickness of the material below the drill reduces thereby increasing the overall stress on the bottom of the plate being drilled. At some point, when the drill tip is at a height $t_{\text {crack }}$ from the exit surface, the von-Mises stress exceeds the flow stress of the material and a crack is initiated near the chisel edge corner to form a small drill cap; the thrust force reduces drastically during this phase $[11,18]$, see point $(B)$ in figure 1 and picture of the small drill cap on titanium alloy from the authors' experimentation.

Figure 1(b) shows the physics used in the model development. However, cutting continues and material is removed by the cutting lips of the drill until the drill point is at a height $t_{\text {deform }}$ above the exit surface when the work done is sufficient to deform the uncut material to form the final exit burr, see point $(C)$ in figure 1 . The thrust forces decrease as the drill exits the work piece and the material below the drill is stretched and bent simultaneously. A second fracture occurs at the corner when the effective plastic strain reaches failure strain of the material. The uncut material is left behind as a burr [19], as shown in figure 1 from point $(C)$ to $(E)$. A bigger drill cap is formed at this stage, see photograph of on top right corner, figure 1 . Thus, in the process, the work involved in the formation of a burr [4] is given as:

$$
\text { Work }_{\text {total }}-\text { Work }_{\text {thrust force }}=\text { Work }_{\text {deformation }}
$$



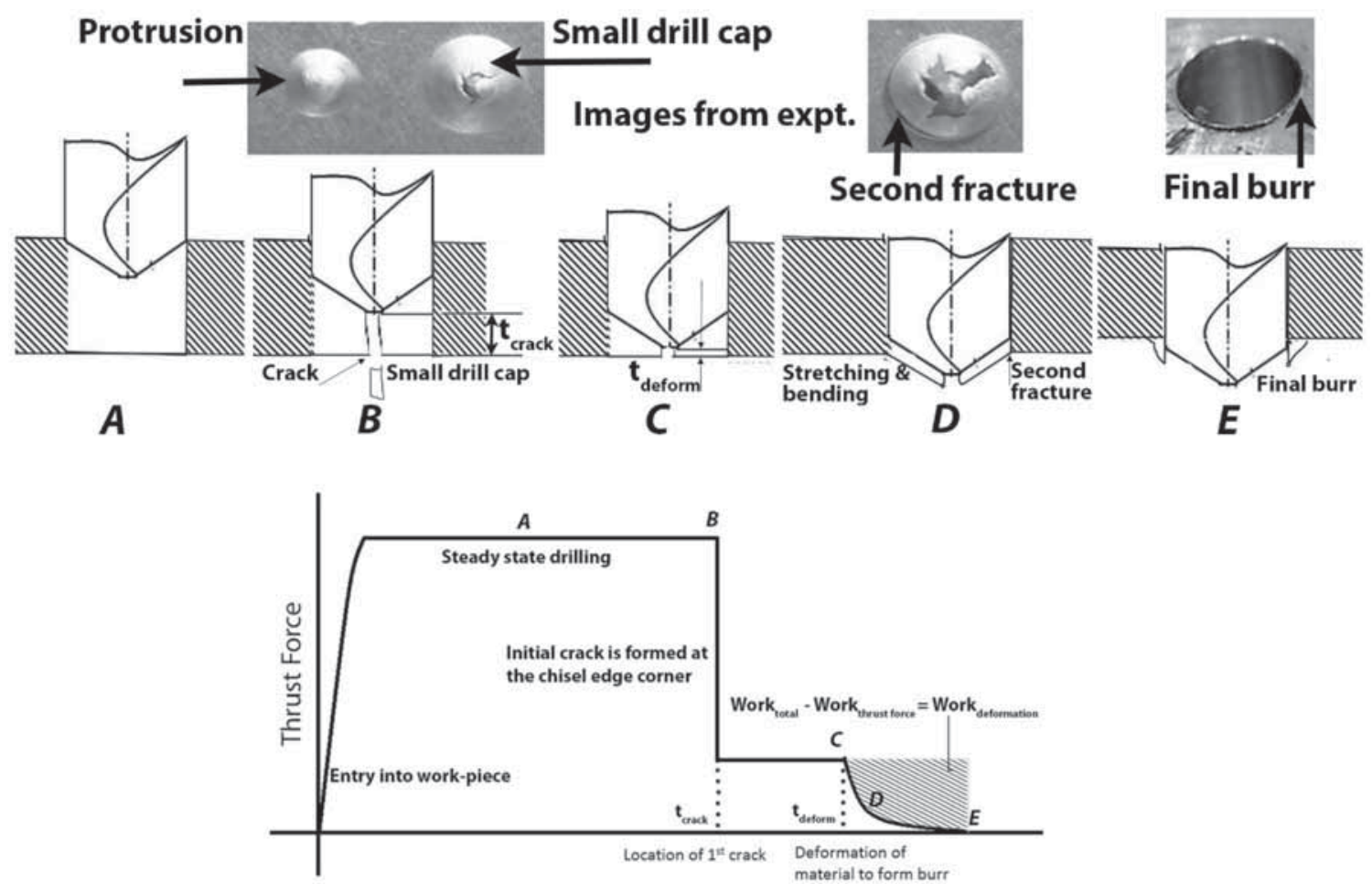

(a) Variation of thrust force and associated phenomena in burr formation process

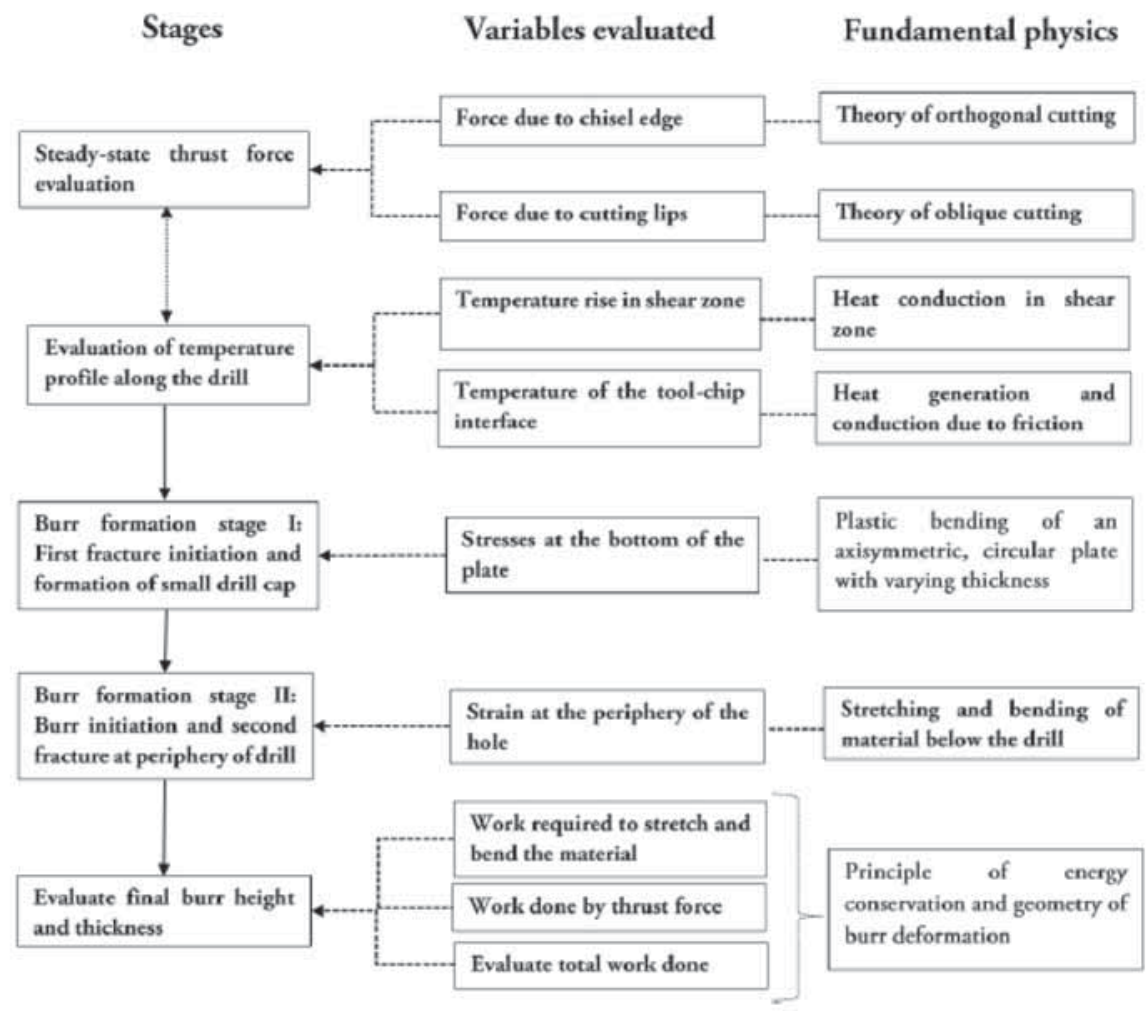

(b) Development of model for burr formation

Figure 1. (a) Various phenomena associated with the burr formation process. (b) Model steps. 
The model approach is elaborated later in various sections.

\section{Foundation for burr formation}

\subsection{Modeling onset of protrusion and formation of small drill cap}

In this model, the physical phenomena of material protrusion and formation of a small drill cap, see figure $1(B)$ and figure 3(a), are modelled as plastic bending of an axisymmetric circular plate of varying thickness, see plate geometry in figure 3(b). The thickness of the plate below the drill is $h_{0}$ till the chisel edge corner, and increases linearly thereafter till the drill periphery. According to the plate geometry shown in figure 2(b), up to the chisel edge the height of the plate is $\mathrm{h}_{0}$ post which it increases linearly with a slope of cot (p). The height of the plate at a distance $r$ from the axis of the drill is given by

$$
\begin{aligned}
& h=h_{0}+\text { flag } *\left(r-L_{c}\right) * \cot (p) \\
& \text { where, flag }= \begin{cases}0, & r \leq L_{c} \\
1, & r>L_{c}\end{cases}
\end{aligned}
$$

As shown in figure 2(a), the length of protrusion which occurs during this stage below the drill axis is very small, compared to the cross-sectional height of the plate as shown in figure 2(b). This situation is analogous to very small vertical deflection of a circular plate of large thickness, where the plasticity theory in conjunction with von-Mises yield criterion can be used to evaluate strain, stress and location of the crack at the bottom surface of the plate being drilled Chakrabarty, [20].

To apply the theory of bending to evaluate the state of stress, and to determine the location of the crack, the thrust forces acting over the cutting edge are considered to be distributed as a pressure, $P_{r}$, over the top surface of the circular plate, figure 2(c), and is given by,

$$
P_{r}=\left\{\begin{array}{l}
\frac{F_{\text {thrust }}^{\text {chiseledge }}}{\pi L_{c}^{2}}, r \leq L_{c} \\
\frac{F_{\text {thrust }}^{\text {cutting }}}{\pi\left(\frac{D}{2}\right)^{2}-\pi L_{c}^{2}}, r>L_{c}
\end{array}\right.
$$

where, the thrust forces due to the chisel edge ( $F_{\text {thrust }}^{\text {chisel }}$ edge $)$ and the cutting lips $\left(F_{\text {thrust }}^{\text {cutting lips }}\right)$ are evaluated as described in section 4.

A free-body diagram of a generic section of the circular plate at a distance $r$ from the drill axis is as shown in figure 2(d). The kinematic and equilibrium conditions for the symmetrical bending of circular plates are formulated with the following assumptions [16]:

a) The vertical displacement of the neutral plane is assumed to be small compared to the thickness of the plate and it effectively remains unstrained during

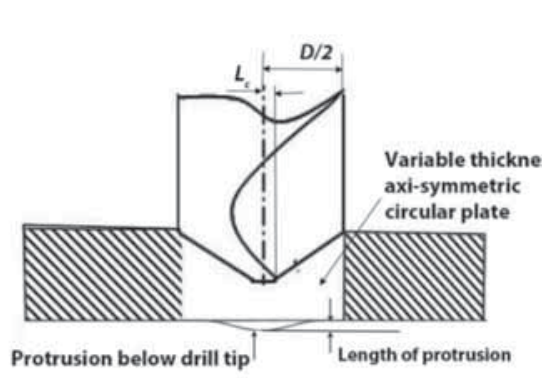

(a)

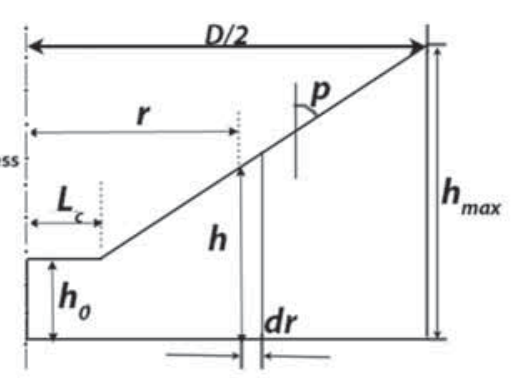

(b)

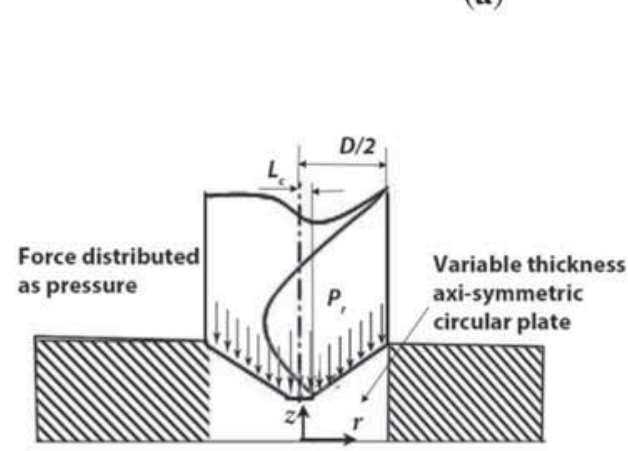

(c)

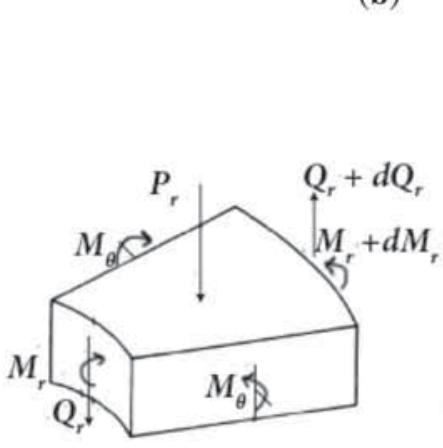

(d)

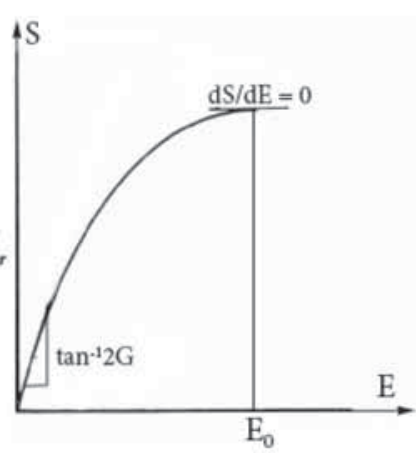

(e)

Figure 2. (a) Circular plate model: geometry and loading. (b) Variation of height. (c) Pressure on circular plate. (d) Free body diagram of an element at distance $r$ from drill axis. (e) Stress-strain diagram. 
bending. Therefore, the quadratic terms due to bending are neglected in the strain formulae.

b) The elongation of the neutral surface and the membrane stresses are neglected.

c) The bottom surface of the plate is free and the thickness of the plate is small as compared to its diameter thus, the normal stress $\sigma_{z}$ is assumed to be zero throughout the plate making it a plane stress problem.

The consideration of equilibrium condition of forces and moments on the circular section yields the following equations [20],

$$
\begin{gathered}
r Q_{r}=\int_{0}^{2 \pi} \int_{0}^{r} P_{r} r d r d \theta \\
\frac{d\left(r M_{r}\right)}{d r}-M_{\theta}+r Q_{r}=0
\end{gathered}
$$

where, at a generic section of the plate moments are defined as [20]

$$
M_{r}=2 \int_{0}^{h} \sigma_{r} z d z ; \quad M_{\theta}=2 \int_{0}^{h} \sigma_{\theta} z d z
$$

In the above equation, $h$ is the thickness of the plate as given by Eq. (2). The geometric equations relating to strain and displacement for the radial and tangential strain are defined as [20]

$$
\varepsilon_{r}=-z \frac{d^{2} w}{d r^{2}} ; \varepsilon_{\theta}=-\frac{z}{r} \frac{d w}{d r}
$$

where, $z$ is the distance from the neutral place. The plastic bending of the plate is modelled as formulated by Merckx [21]. The second stress invariant, $S$, is assumed to be a function of the second strain invariant, $E$, given by the following relationship [21], and as shown in figure 2(e)

$$
S=2 G\left[1-\frac{E^{2}}{3 E_{0}^{2}}\right] E
$$

where, $G$ is the shear modulus. The second stress and strain invariants follow a non-linear relationship and the curve is horizontal at $E=E_{0}$, the maximum permissible strain invariant.

From the assumption that $\sigma_{z}$ is zero and the material is incompressible, the second stress and strain invariants in terms of radial and circumferential stresses and strain are given by [21]

$$
S^{2}=\frac{1}{3}\left[\sigma_{r}^{2}-\sigma_{r} \sigma_{\theta}+\sigma_{\theta}^{2}\right] \text { and } E^{2}=\varepsilon_{r}^{2}+\varepsilon_{r} \varepsilon_{\theta}+\varepsilon_{\theta}^{2}
$$

To evaluate the shear force per unit length of the plate, the pressure distribution equation ((3) is substituted into the force equilibrium equation),

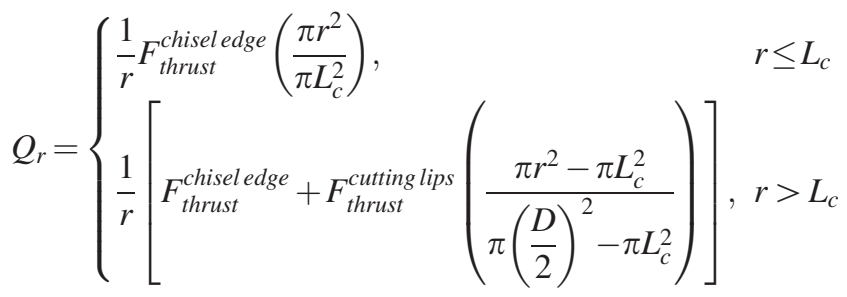

Assuming the stress deviators to be proportional to the corresponding strain deviators, and using the stress-strain relationship defined by Eq. (8) and the stress equation (9), the principal stresses $\sigma_{r}$ and $\sigma_{\theta}$ are expressed in terms of the principal strains and are given by the following expressions [21]

$$
\begin{aligned}
& \sigma_{r}=4 G\left[1-\frac{\varepsilon_{r}^{2}+\varepsilon_{r} \varepsilon_{\theta}+\varepsilon_{\theta}^{2}}{3 E_{0}^{2}}\right]\left(\varepsilon_{r}+\frac{\varepsilon_{\theta}}{2}\right) \\
& \sigma_{\theta}=4 G\left[1-\frac{\varepsilon_{r}^{2}+\varepsilon_{r} \varepsilon_{\theta}+\varepsilon_{\theta}^{2}}{3 E_{0}^{2}}\right]\left(\varepsilon_{\theta}+\frac{\varepsilon_{r}}{2}\right)
\end{aligned}
$$

The bending moments (Eq. (6)) are expressed in terms of vertical displacement, $w$, by substituting strain-displacement relationship (Eq. (7)) in the equations for stress (Eq. (11)). Further, the differential equation for plastic bending of circular plate is obtained by substituting the bending moment equations (6) in the equation for moment equilibrium ((5) and using the expression for shear force per unit length (Eq. (10))) as given by,

$$
\begin{aligned}
& \frac{d^{3} w}{d r^{3}}+\frac{1}{r} \frac{d^{2} w}{d r^{2}}-\frac{1}{r^{2}} \frac{d w}{d r}=\frac{3 Q_{r}}{8 h^{3} G}+\frac{d}{d r}\left\{\left[\frac{d^{2} w}{d r^{2}}+\frac{1}{2 r} \frac{d w}{d r}\right]\right. \\
& \left.\frac{h^{2}}{5 E_{0}^{2}}\left[\left(\frac{d^{2} w}{d r^{2}}\right)^{2}+\left(\frac{d^{2} w}{d r^{2}}\right)\left(\frac{1}{r} \frac{d w}{d r}\right)+\left(\frac{1}{r} \frac{d w}{d r}\right)^{2}\right]\right\} \\
& +\frac{1}{2}\left\{[ \frac { 1 } { r } \frac { d ^ { 2 } w } { d r ^ { 2 } } - \frac { 1 } { r ^ { 2 } } \frac { d w } { d r } ] \frac { h ^ { 2 } } { 5 E _ { 0 } ^ { 2 } } \left[\left(\frac{d^{2} w}{d r^{2}}\right)^{2}\right.\right. \\
& \left.\left.+\left(\frac{d^{2} w}{d r^{2}}\right)\left(\frac{1}{r} \frac{d w}{d r}\right)+\left(\frac{1}{r} \frac{d w}{d r}\right)^{2}\right]\right\}
\end{aligned}
$$

In order to reduce the above third order differential equation to a second order differential, the slope of the displacement is replaced with a new variable, i.e.,

$$
\phi=\frac{d w}{d r}
$$

$$
\begin{aligned}
\phi^{\prime \prime} & +\frac{\phi^{\prime}}{r}-\frac{\phi}{r^{2}} \\
& =\frac{3 Q_{r}}{8 h^{3} G}+\frac{d}{d r}\left\{\frac{h^{2}}{5 E_{0}^{2}}\left[\phi^{\prime}+\frac{\phi}{2 r}\right]\left[\phi^{\prime 2}+\frac{\phi^{\prime} \phi}{r}+\left(\frac{\phi}{r}\right)^{2}\right]\right\} \\
& +\frac{1}{2}\left\{\frac{h^{2}}{5 E_{0}^{2}}\left[\frac{\phi \prime}{r}-\frac{\phi}{r^{2}}\right]\left[\phi^{\prime 2}+\frac{\phi^{\prime} \phi}{r}+\left(\frac{\phi}{r}\right)^{2}\right]\right\}
\end{aligned}
$$


Using the solution of the differential equation, i.e., $\phi$, along with the strain-displacement relation (Eq. (7)) and stress-strain relationship (Eq. (11)), the von-Mises stress ( $\sqrt{3} S$, Eq. 9) at the bottom surface of the plate is evaluated.

\subsection{Initiation of burr formation and exit burr size}

The initial deformation of the material is assumed to begin when the drill tip is at a height $t_{\text {deform }}$ above the bottom surface of the plate being drilled, denoted by position $A$ in figure 3(a). The deformation consists of stretching of the material from $a b c d \rightarrow h b c k$ and bending along $b c$ as the drill moves to position $B$, figure 3(a). The stretching and bending occur simultaneously in this process. The material is then stretched and bent to efgbh and finally pushed downwards by the drill stretching the material and forming a large drill cap besides final burr, as shown in figure 3(b).

To model the burr formation phenomena in this stage, principle of energy conservation as proposed by Kim and Dornfeld [4] has been used. According to this principle, the total work done in the burr formation process is equal to the sum of the work done by thrust forces and the work required to stretch and bend the material during the exit stage drilling.

(a)

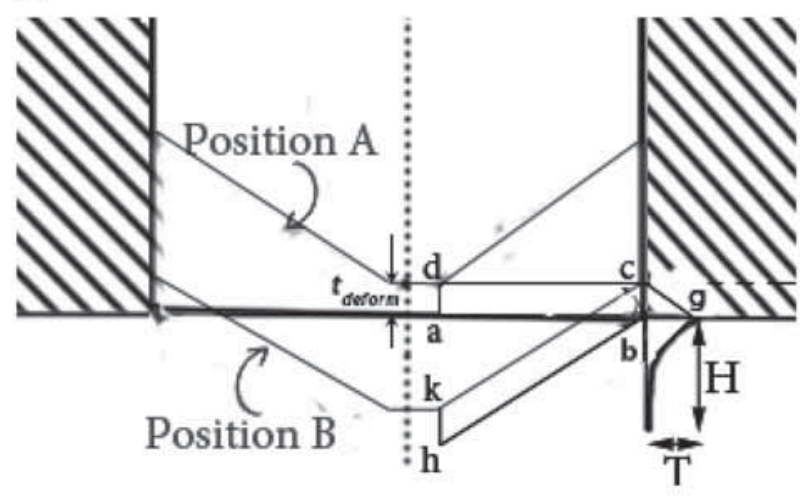

(b)

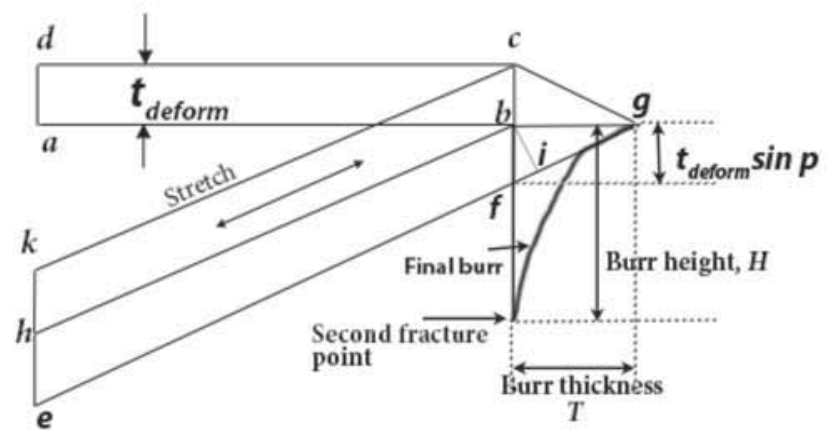

Figure 3. (a) Burr initiation point. (b) Final burr formation geometry.

$$
\Delta W_{\text {total }}=\Delta W_{\text {thrust force }}+\Delta W_{\text {deform }}
$$

However, based on the understanding of the variation in thrust force and formation of a small drill cap, few modifications are made to their model. This model considers the variation in thrust force due to small drill cap formation as well as the variation in thrust force as the drill exits the work surface. The model also incorporates the volume reduction of the material below the drill, due to formation of a small drill cap. Kim and Dornfeld [4] have not considered the formation of a small drill cap and therefore, a reduction in volume will modify the work required to deform the material as compared to the work evaluated by them. The total work required to deform the material is expressed as a sum of the work required to stretch the material and the work required to bend the material around the drill corner.

$$
\Delta W_{\text {deform }}=\Delta W_{\text {stretch }}+\Delta W_{\text {bend_bc }}
$$

In the following paragraphs, the variation in thrust force and the work done to deform the material is explained. The burr initiation point, $t_{\text {deform }}$, is evaluated using the principle of energy conservation as described by Eq. (15).

The thrust force decreases rapidly after the formation of a small drill cap. Also, as the drill exits the work surface, the amount of material cut by the cutting lips decreases with each step, as shown in figure 4 such that $y_{1}>y_{2}$ $>y_{3}>y_{4}$. The thrust force due to the cutting lips, for the length of the material being cut, is calculated using the principles of orthogonal cutting as described in section 4.2 of forces due to the cutting lips. Equation (17) is an empirical relation found out from experimental data of the thrust force at the exit. The variation in thrust force during the exit stage drilling is approximated as,

$$
F_{\text {thrust }}^{\text {exit }}=F_{\text {thrust }}^{\text {cutting_lips }}\left[1-\left(\frac{y}{t_{\text {deform }}+\frac{R}{\tan p}}\right)^{1 / 3}\right]
$$

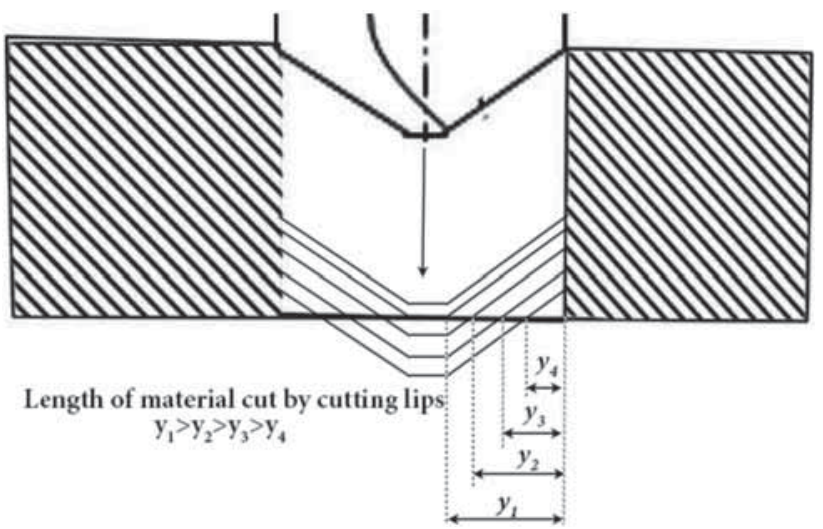

Figure 4. Cutting during exit of drill from work surface. 
where, $F_{\text {thrust }}^{\text {cutting lips }}$ is the thrust force due to the entire cutting lips and is given by Eq. (34).

Thus, the work done by the thrust force is evaluated as given below,

$$
\begin{aligned}
& \Delta W_{\text {thrust_force }} \\
& =\int_{0}^{t_{\text {deform }}+\frac{R}{\text { tan } p}} F_{\text {thrust }}^{\text {cutting lips }}\left[1-\left(\frac{y}{t_{\text {deform }}+\frac{R}{\tan p}}\right)^{1 / 3}\right] d y \\
& =\frac{1}{4} F_{\text {thrust }}^{\text {cutting lips }}\left(t_{\text {deform }}+\frac{R}{\tan p}\right)
\end{aligned}
$$

The work required to deform the material consists of the work required to stretch the material and the work required to bend the material around the drill corner. However, the material removed due to formation of a small drill cap does not contribute to the work required to deform the material below the drill. Therefore, the geometry of work-material considered for stretching and bending involves an annular circulate plate of diameter $D / 2$ with a hole of diameter equal to the chisel edge length $2 L_{c}$. The work required to bend the material along the drill corner is given by [4],

$$
\Delta W_{\text {bend_bc }}=M_{b} \Delta \theta=\left(\frac{1}{2} \pi R \bar{\sigma}_{f} t_{\text {deform }}^{2}\right)\left(\frac{\pi}{2}-p\right)
$$

where, $M_{b}$ is the bending moment $\left(\frac{1}{2} \pi R \bar{\sigma}_{f} t_{\text {deform }}^{2}\right)$ and $\Delta \theta$ is the angle of rotation $\left(\frac{\pi}{2}-p\right)$. The flow stress of the material is assumed to be constant at a mean value of $\bar{\sigma}_{f}$ along the length of work-material. The work required to stretch workmaterial from $a b c d \rightarrow e g b h$ is given by,

$$
\Delta W_{\text {stretch }}=\int_{L_{c}}^{R} \sigma_{f} \varepsilon(r) d V
$$

where, $\varepsilon(r)$ is the strain along the length of the material due to stretching. The mean strain due to stretching is calculated using the geometry [4], figure 3(b). Point $b$ moves to point $i$ and point $h$ moves to point $e$.

$$
\begin{aligned}
\overline{\varepsilon(r)} & =\ln \frac{\frac{R}{\sin p}+t_{\text {deform }} \sin p \cos p}{R} \\
& \cong \ln \left(\frac{1}{\sin p}\right)+\frac{t_{\text {deform } \sin ^{2} p \cos p}}{R}
\end{aligned}
$$

The strain is not uniform along the length of the plate. It is assumed to be maximum at the centre of the plate and zero at the drill corner. The strain at a distance $r$ from the drill axis is given by [4, 22],

$$
\varepsilon(r)=\frac{3}{2}\left[\ln \left(\frac{1}{\sin p}\right)+\frac{t_{\text {deform }} \sin ^{2} p \cos p}{R}\right]\left[1-\frac{r^{2}}{R^{2}}\right]
$$

The work required to stretch the material is evaluated by substituting the strain along the length of the plate given by Eq. (22) in Eq. (20).

$$
\begin{aligned}
\Delta W_{\text {stretch }}= & \frac{3 \pi \bar{\sigma}_{f} t_{\text {deform }}}{4}\left[\ln \left(\frac{1}{\sin p}\right)+\frac{t_{\text {deform }} \sin ^{2} p \cos p}{R}\right] \\
& {\left[R^{2}-L_{c}^{2}\left(2-\frac{L_{c}^{2}}{R^{2}}\right)\right] }
\end{aligned}
$$

The total work required to stretch and bend the material is given by the substituting Eq. (19) and Eq. (23) in Eq. (16).

$$
\begin{aligned}
\Delta W_{\text {deform }}= & \frac{3 \pi \bar{\sigma}_{f} t_{\text {deform }}}{4}\left[\ln \left(\frac{1}{\sin p}\right)+\frac{t_{\text {deform }} \sin ^{2} p \cos p}{R}\right] \\
& {\left[R^{2}-L_{c}^{2}\left(2-\frac{L_{c}^{2}}{R^{2}}\right)\right]+\frac{1}{2} \pi R \bar{\sigma}_{f} t_{\text {deform }}^{2}\left(\frac{\pi}{2}-p\right) }
\end{aligned}
$$

The total work done during the exit stage deformation is given by

$$
\Delta W_{\text {total }}=F_{\text {thrust }}^{\text {cutting lips }}\left(t_{\text {deform }}+\frac{R}{\tan p}\right)
$$

The value of $t_{\text {deform }}$ is evaluated by solving the quadratic equation obtained by substituting the equations for the total work done (Eq. (25)), work done to deform the material (Eq. (24)) and the work done by the thrust force (Eq. (18)) in the energy conservation equation (Eq. (15)). The final expression for $t_{\text {deform }}$ is given by,

$$
t_{\text {deform }}=\frac{-b+\sqrt{b^{2}-4 a c}}{2 a}
$$

where, the constants of the quadratic equation are

$$
\begin{aligned}
a= & \frac{1}{2} \pi R \bar{\sigma}_{f}\left(\frac{\pi}{2}-p\right) \\
& +\frac{3}{4} \pi \bar{\sigma}_{f} \frac{\sin ^{2} p \cos p}{R}\left[R^{2}-L_{c}^{2}\left(2-\frac{L_{c}^{2}}{R^{2}}\right)\right], \\
b= & -\frac{3}{4} F_{\text {thrust }}^{\text {cutting lips }} \\
& +\frac{3}{4} \pi \bar{\sigma}_{f} \ln \left(\frac{1}{\sin p}\right)\left[R^{2}-L_{c}^{2}\left(2-\frac{L_{c}^{2}}{R^{2}}\right)\right] \text { and } c \\
= & -\frac{3}{4} F_{\text {thrust }}^{\text {cutting lips }}\left(\frac{R}{\tan p}\right)
\end{aligned}
$$

As the drilling progresses, the material is further stretched by the drill at the periphery of the hole. At some instant, the effective plastic strain at the periphery reaches the failure strain, $\varepsilon_{f}$, of the material [4]. At this point a second fracture occurs, as shown in figure 3(b), and a large drill cap is formed. The remaining work-material develops a burr at the periphery, as shown in figure 3(b). The burr thickness $(T)$ and height $(H)$ are shown in figure 3(b). Since the material is assumed to be incompressible, principle of volume conservation gives the following: $d V=0, d \varepsilon_{\theta}=0$ and $d \varepsilon_{r}=-d \varepsilon_{z}$. The effective plastic strain at the region of fracture is given by [4], 


$$
\bar{\varepsilon}_{p}=\frac{2 \sqrt{3}}{3} \varepsilon_{z}
$$

The material stretches from length $b f$ to length $H$, at which a fracture occurs as $\bar{\varepsilon}_{p} \rightarrow \varepsilon_{f}$ and a burr is formed. The strain, $\varepsilon_{z}$, at this instant calculated using the geometry is given by [4],

$$
\varepsilon_{z}=\ln \left(\frac{H}{t_{\text {deform }} * \operatorname{sinp}}\right)
$$

The burr height $(H)$ is evaluated by substituting Eq. (28) in Eq. (27) and equating it to the failure strain and the burr thickness $(T)$ is evaluated from the geometry [4], figure 3.

$$
\begin{aligned}
& T=t_{\text {deform }} * \sin p * \tan p \\
& H=t_{\text {deform }} * \sin p * e^{\frac{\sqrt{3}}{2} \varepsilon_{f}}
\end{aligned}
$$

\section{Evaluation of thrust forces and temperature}

\subsection{Force due to chisel edge}

The chisel edge is divided into several elementary sections of length $d r$ and the forces are evaluated using Merchant's circle of forces for orthogonal cutting. The total thrust force due to the chisel edge is found by summing the forces on all the elementary segments up to the corner of the chisel edge, given by [23]

$$
\begin{gathered}
F_{\text {thrust }}^{\text {chisel edge }}=2 \int_{R_{\text {ind }}}^{L_{c}} d F_{s} \frac{\sin \left(\beta_{n}-\gamma_{e}+\eta\right)}{\cos \left(\phi_{n}+\beta_{n}-\gamma_{e}\right)} \\
d F_{s}=\frac{k_{s} f \cos \eta d r}{2 * \sin \phi_{n}}, \quad \gamma_{e}=-\left(\left|\gamma_{n}\right|-\eta\right), \quad \eta=\tan ^{-1} \frac{f N}{2 \pi r N}, \\
\gamma_{n}=-\tan ^{-1}[\tan (p) * \cos (\pi-\varphi)] \text { and } R_{\text {ind }}=\frac{f}{2 \pi} \tan \left(\theta_{w}\right)
\end{gathered}
$$

where,

$R_{\text {ind }}$ is the length over which the extrusion occurs [24]. However, this length is very small as compared to the length of the chisel edge hence has insignificant contribution to the torque. The thrust force contribution is $2-4 \%$ of the total thrust force due to chisel edge [25], therefore this region is not considered in the present study.

The shear angle $\left(\phi_{n}\right)$ is determined by the Ernst-Merchant equation [26] $\phi_{n}=\frac{\pi}{4}+\frac{\gamma_{e}}{2}-\frac{\beta_{n}}{2}$. The normal friction angle is assumed to be dependent on the coefficient of friction and is evaluated as $\beta_{n}=\tan ^{-1} \mu$. The friction force on the elementary element of length $d r$, machining stain and the chip velocity are evaluated using the Merchant's circle and principle of metal cutting, given by the following expressions [27],

$$
\begin{aligned}
d F_{\text {friction }}^{\text {chiseledge }} & =\frac{k_{s} f \cos \eta d r}{2 * \sin \phi_{n}} * \frac{\sin \left(\beta_{n}\right)}{\cos \left(\phi_{n}+\beta_{n}-\gamma_{e}\right)}, \varepsilon \\
& =\frac{\cos \gamma_{e}}{\sin \phi_{n} * \cos \left(\phi_{n}-\gamma_{e}\right)} \text { and } V_{\text {chip }}^{\text {chisel edge }} \\
& =\frac{2 \pi r N \sin \phi_{n}}{\cos \left(\phi_{n}-\gamma_{e}\right)}
\end{aligned}
$$

\subsection{Force due to cutting lips}

The cutting lips is divided into several elementary elements and the total thrust force is found by summing the forces on all these elementary segments up to the corner of the drill as given by [28],

$$
F_{\text {thrust }}^{\text {cutting lips }}=2 \int_{L_{c}}^{D / 2} \bar{F}_{T} \cos p+\bar{F}_{R} \sin p
$$

where, the mutually perpendicular forces $\bar{F}_{C}, \bar{F}_{T}$ and $\bar{F}_{R}$ and are given by the expressions [28],

$$
\begin{aligned}
\bar{F}_{c} & =\frac{d F s * \cos \left(\beta_{n}-\gamma_{e}\right)}{\cos \left(\phi_{n}+\beta_{n}-\gamma_{e}\right)}, \bar{F}_{T}=\frac{d F s * \sin \left(\beta_{n}-\gamma_{e}\right)}{\cos \left(\phi_{n}+\beta_{n}-\gamma_{e}\right)} \\
\bar{F}_{R} & =\frac{\bar{F}_{c}\left(\sin i-\cos i \sin \gamma_{e} \tan \eta_{c}\right)-\bar{F}_{T}\left(\cos \gamma_{e} \tan \eta_{c}\right)}{\operatorname{sinisin} \gamma_{e} \tan \eta_{c}+\cos i} \\
d F_{s} & =\frac{k_{s} f \sin p \cos \left\{\tan ^{-1}\left[\left(\sin ^{-1} \frac{w}{r}\right) \cos p\right]\right\} r d r}{2 * \sin \phi_{n} * \sin p * \sqrt{r^{2}-w^{2}}}
\end{aligned}
$$

The chip flow angle $\left(\eta_{c}\right)$, inclination angle $(i)$, the effective rake angle $\left(\gamma_{e}\right)$ are a function of the intermediate angles as given below,

$$
\begin{aligned}
\eta_{c} & =\tan ^{-1}\left(\tan i * \sin \gamma_{e}\right), i=\sin ^{-1}(\sin \omega \sin p), \gamma_{e} \\
& =\gamma_{\text {ref }}-\varepsilon
\end{aligned}
$$

where, $\gamma_{r e f}=\tan ^{-1}\left(\frac{\tan \delta \cos \omega}{\sin p-\tan \delta \sin \omega \cos p}\right), \delta=\tan ^{-1}\left(\frac{2 r \tan \delta_{0}}{D}\right)$, $\varepsilon=\tan ^{-1}(\tan \omega \cos p)$ and $\omega=\sin ^{-1}\left(\frac{w}{r}\right)$

The friction force on an elementary particle of length $d l$ and the chip velocity are obtained using the principles of metal cutting in oblique cutting are given by [29],

$$
\begin{aligned}
& d F_{\text {friction }}^{\text {cutting lips }} \\
& =\frac{\bar{F}_{T}\left(\cos \gamma_{e} * \cos i\right)+\bar{F}_{c} \sin \gamma_{e}}{\cos ^{2} \gamma_{e} \cos i \cos \eta_{c}+\sin \gamma_{e}\left(\sin i \sin \eta_{c}+\sin \gamma_{e} \cos i \cos \eta_{c}\right)}, \\
& V_{\text {chip }}^{\text {cutting lips }}=\frac{2 \pi r N \cos i \sin \phi_{n}}{\cos \eta_{c} \cos \left(\phi_{n}-\gamma_{e}\right)}
\end{aligned}
$$

\subsection{Temperature in drilling}

To model the temperature profile along the cutting edge, the drill cutting edge including the cutting lips 


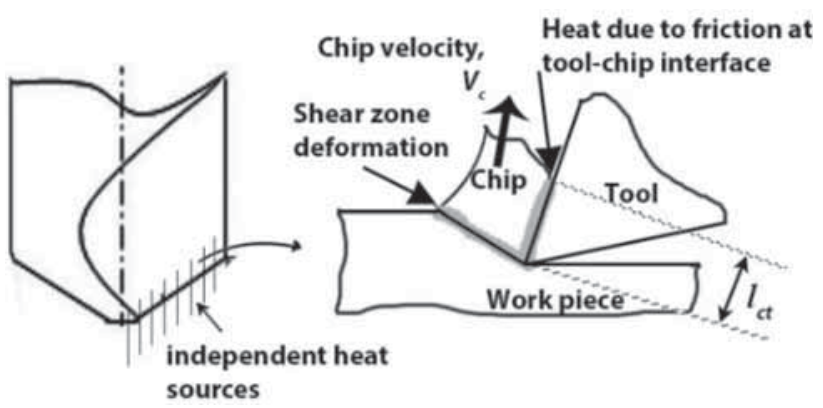

Figure 5. Elementary particle heat generation zones.

and the chisel edge are divided into several elements that act as independent heat sources, as shown in figure 5. An increase in the temperature during drilling is primarily due to deformation in the shear zone and the heat generated over the chip-tool interface because of friction. Therefore, the total temperature can be expressed as

$$
T_{\text {total }}=\Delta T_{s}+\Delta T_{c t}+T_{\text {room }}
$$

where, $\Delta T_{s}$ is the temperature rise in the shear zone and $\Delta T_{c t}$ is the temperature rise due to friction between chiptool interface.

The temperature rise in the primary shear zone is given by [30],

$$
\Delta T_{s}=\frac{1}{1+\frac{3}{4} \sqrt{\frac{\pi \alpha_{w} V_{s}}{a_{0} V^{2} \sin \left(\phi_{n}\right)}}} \frac{k_{s} A_{s} V_{s}}{\rho_{w} S_{w} A V}
$$

The temperature rise due to the heat generated due to friction is given by [23],

$$
\Delta T_{c t}=\frac{4}{3} \frac{q_{\text {friction }} \sqrt{\frac{l_{c}}{\pi V_{\text {chip }} K_{w} \rho_{w} S_{w}}}}{1+\frac{2}{3} \sqrt{\frac{l_{c} K_{t} \rho_{t} S_{t}}{t V_{c h i p} K_{w} \rho_{w} S_{w}}}}
$$

where, the total heat generation flux is given by,

$$
q_{\text {friction }}^{\prime \prime}=\frac{d F_{\text {friction }} * V_{\text {chip }}}{l_{c t} * d l}
$$

$d F_{\text {friction }}$ is the friction force between the tool and the chip on an element of length $d l$ as given by Eq. (33) and Eq. (37), and $l_{c t} * d l$ is the tool-chip interface area.

The total temperature of the chip is evaluated by substituting Eq. (36) and Eq. (37) in Eq. (35). Various steps adopted to develop a MATLAB code to evaluate the thrust forces, the temperature profile along radius of the drill, protrusion below the drill tip, which finally helps to evaluate burr exit, burr size are presented in Appendix - A.

\section{Model analysis}

\subsection{Analysis of small drill cap formation}

The protrusion of the material along the radius of the drill and as a function of the distance of drill tip, $h$, measured from the bottom surface of the plate is as shown in Figure 6. The protrusion is maximum at the axis of the drill and is profound over the chisel edge region. A high pressure force is concentrated over the chisel edge region which significantly increases the von-Mises stresses over the chisel edge region compared to the cutting lips region, figure 7. The maximum von-Mises stress increases from

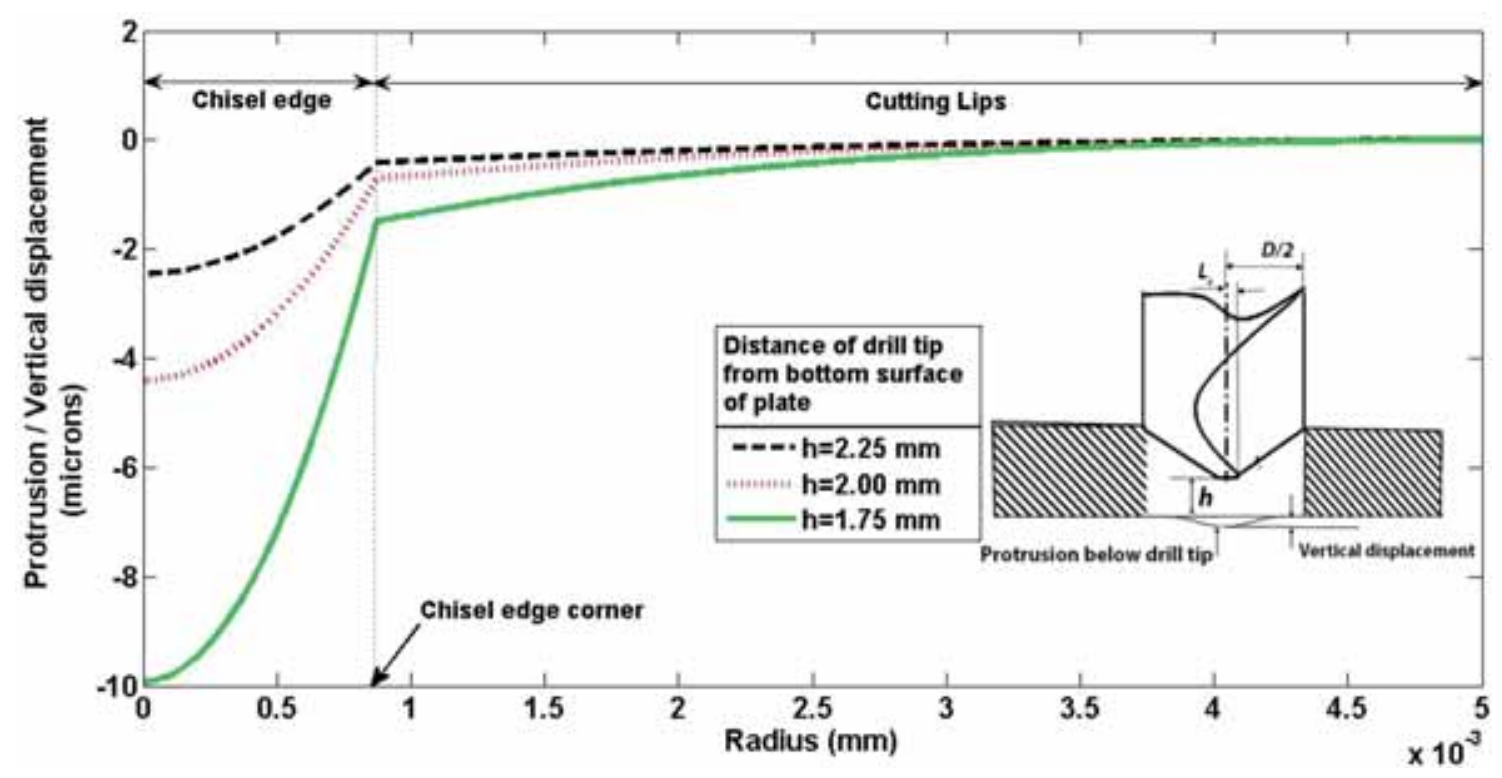

Figure 6. Protrusion modelled as vertical displacement along bottom surface of the plate. 


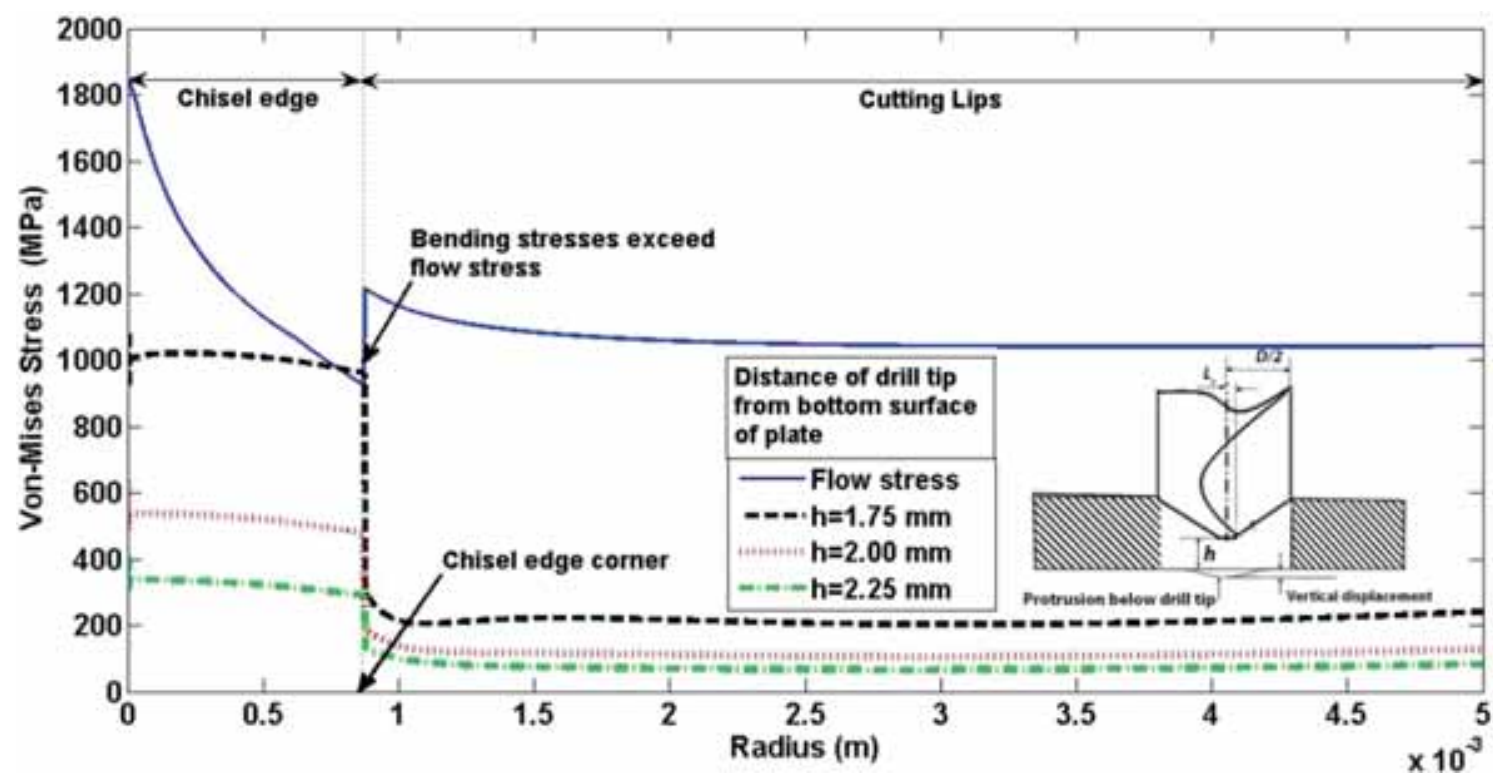

Figure 7. Evolution of bending stress at the bottom surface as a function of the distance of drill tip from bottom surface of plate.

$375 \mathrm{MPa}$ to $1000 \mathrm{MPa}$ as the drill moves downwards from a height of $2.25 \mathrm{~mm}$ to a height of $1.75 \mathrm{~mm}$. At this instant, the bending stresses exceed the flow stress of the material and a fracture is initiated at the chisel edge corner leading to formation of a small drill cap.

A parameter that affects the thrust force or the rigidity of the work-material below the drill is likely to influence the distance of drill tip measured from the bottom surface of the plate $(h)$ at which a fracture initiates at the chisel edge corner. For a given distance of the drill tip $(h=2 \mathrm{~mm})$, the bending stresses are higher at higher feed due to larger comparative thrust forces, figure 8 . Therefore, at a feed of $0.25 \mathrm{~mm} / \mathrm{rev}$, the smaller drill cap is formed at a height of $h=2 \mathrm{~mm}$ (figure 8 ) whereas, at a feed of $0.1 \mathrm{~mm} / \mathrm{rev}$ it is formed at $h=1.75 \mathrm{~mm}$ (figure 7).

\subsection{Analysis of burr initiation point and the work done}

The total work done during exit of the drill from the workpiece increases with an increase in feed and drill diameter, figure 9(a). The distance of the drill tip, measured from the exit surface, at the burr initiation point $\left(t_{\text {deform }}\right)$ increases with an increase in feed but remains almost independent of the changes in the drill diameter. At higher feeds, the cutting pressure increases, due to larger thrust forces, and are capable of deforming larger volume of material, possibly increasing $t_{\text {deform }}$. The cutting pressure remains more or less constant with a variation in drill diameter therefore, results in no variation in $t_{\text {deform }}$.

The reduced length of the cutting lips, with an increase in the point angle, limits the extent to which the layer beneath the drill tip is bent and stretched, thus reducing the corresponding work done, figure 9(b). However, the burr initiation point $\left(t_{\text {deform }}\right)$ is observed to increase with an increase in the point angle as the cutting pressure increases.

The work done during the exit of drill comprises of the work done by the thrust forces and the work done to bend and stretch the material below the drill tip. Figure 10 shows the contribution of these components as a percentage of the total work.

The work done by the thrust forces remains about $25 \%$, as evident from Eq. (18) and Eq. (25). Further, the work done in stretching reduces from $73 \%$ to $68 \%$ of the total work done as the feed increases from $0.05 \mathrm{~mm} / \mathrm{rev}$ to $0.25 \mathrm{~mm} / \mathrm{rev}$. At the same time, the work done in bending increases from $2 \%$ to $7 \%$. Similar percentage distribution is observed for variation in drill diameter, point angle, helix angle, chisel edge angle and web ratio. However, these plots are not shown here. On average, the work done in stretching the material is about $70 \%$ of the total work done while the work done in bending the material is about $5 \%$ of the total work done during the exit stage drilling.

\subsection{Parameters affecting burr size}

In general, larger the thickness of the layer $\left(t_{\text {deform }}\right)$ results in larger the burr size. A variation of burr height and thickness with various parameters is shown in figures 11(a)-(f). In evaluating the analytical results, one parameter is varied at a time, while all other parameters are held at their central levels. The burr size increases with an increase in feed, figure 11(a). As explained earlier, a higher cutting pressure results in early deformation of the material resulting in larger burr size. The trend observed is linear, the burr height increases from $50 \mu \mathrm{m}$ to $250 \mu \mathrm{m}$ as the feed 


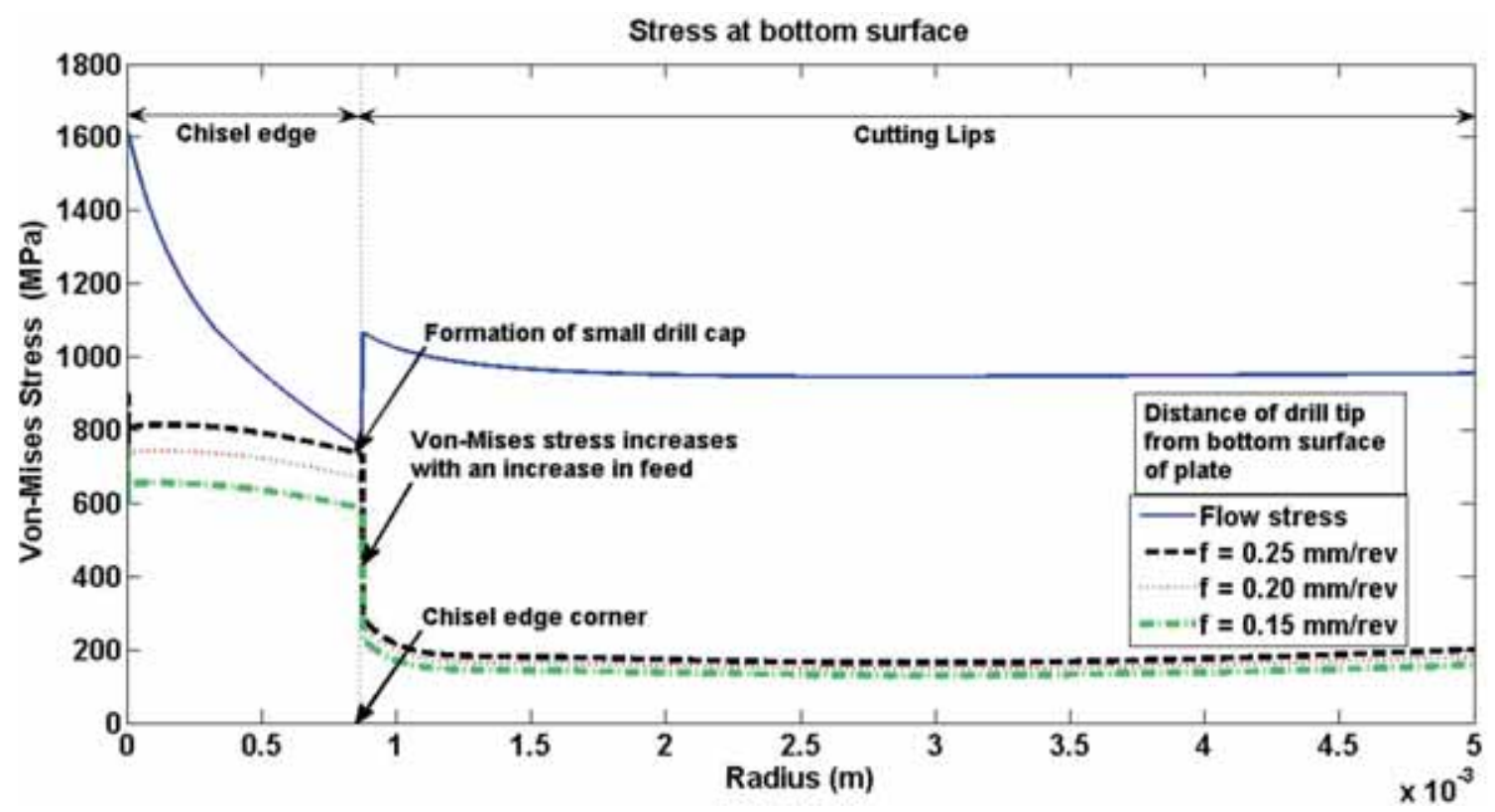

Figure 8. Evolution of bending stress along the bottom surface with variation in feed at a given distance of drill tip from the bottom surface of the plate $(h=2 \mathrm{~mm})$.

(a)

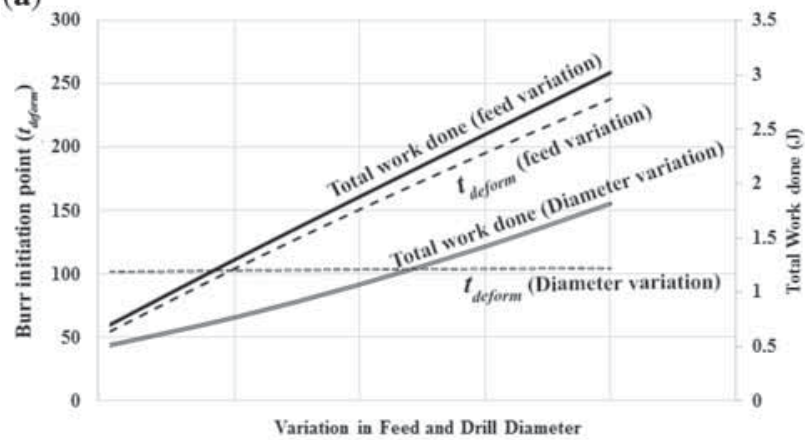

(b)

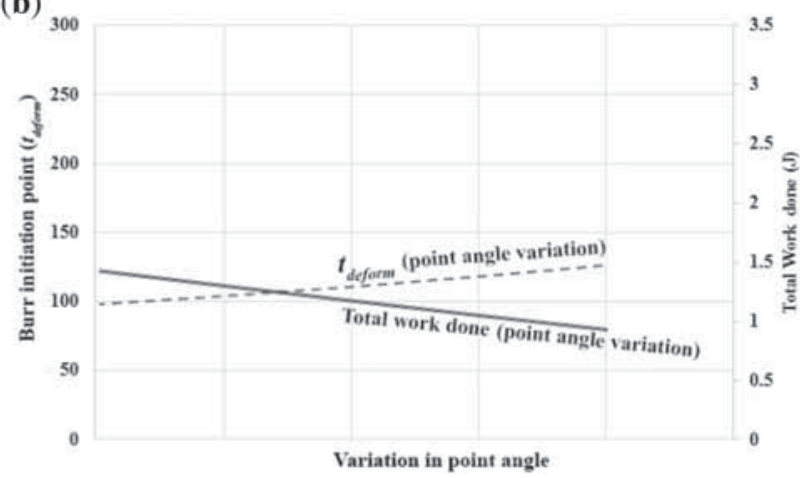

Figure 9. Work done and burr initiation point with variation in (a) feed and drill diameter and (b) point angle.

increases from $0.5 \mathrm{~mm} / \mathrm{rev}$ to $2.5 \mathrm{~mm} / \mathrm{rev}$, while the burr thickness increases from $90 \mu \mathrm{m}$ to $350 \mu \mathrm{m}$ for the same change in feed rate.

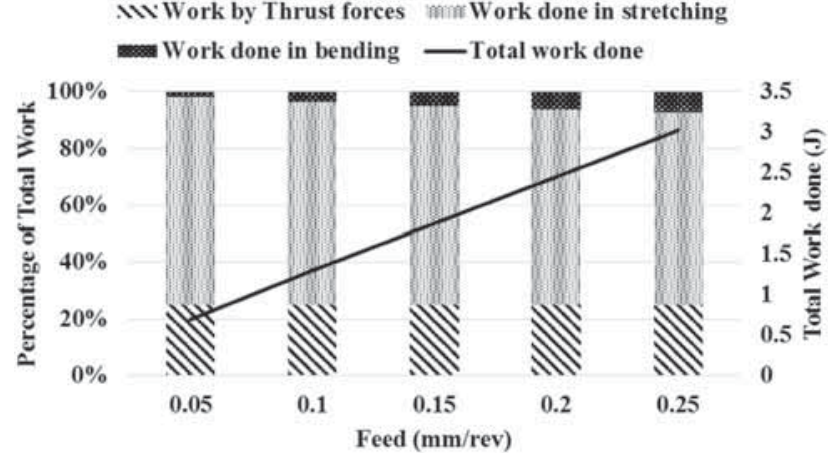

Figure 10. Total work done and work segmentation in exit stage drilling.

The burr size predicted by the model is almost constant with changes in the cutting speed, figure 11(b). This could be because of thermal softening of work material and the resulting decrease in thrust forces and cutting pressure. For a given thrust force, burr initiation will be earlier for a softer material, but a reduction in thrust forces with an increase in cutting speed compensates for this change. Burr size increases with an increase in the point angle, figure 11(c), decreases with an increase in helix angle, figure 11(d) and remains almost constant with a variation in drill diameter, figure 11(e), and web ratio, figure 11(f). These trends can be explained based on either an increase, decrease or constant cutting pressure with variation in point angle, helix angle, drill diameter and web ratio, as explained earlier. 
(a)

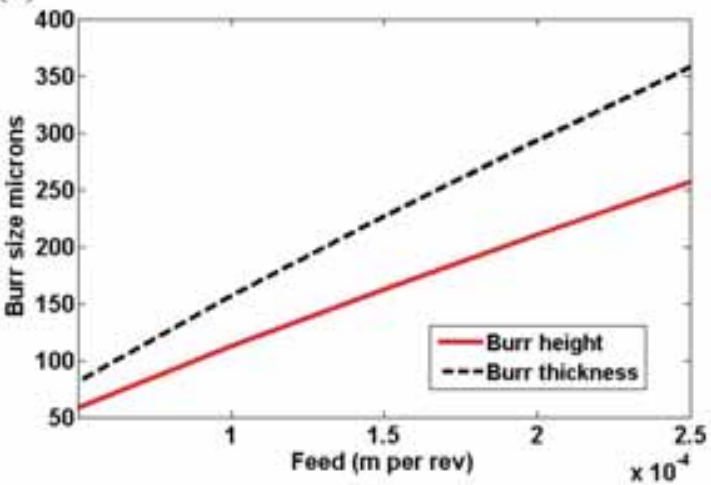

(c)

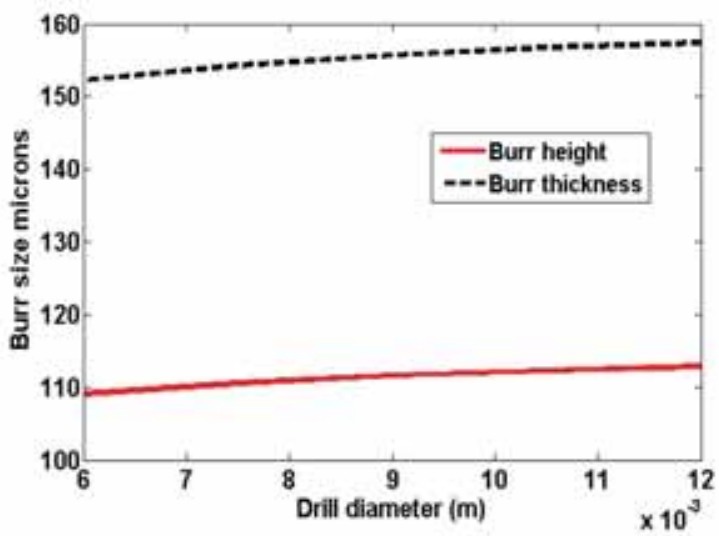

(e)

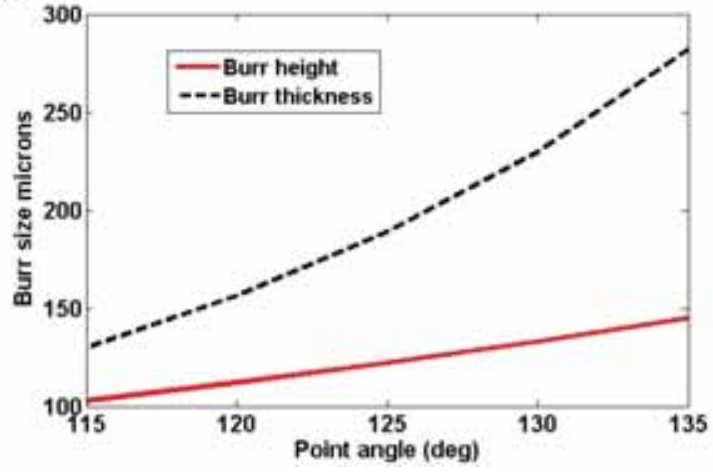

(b)

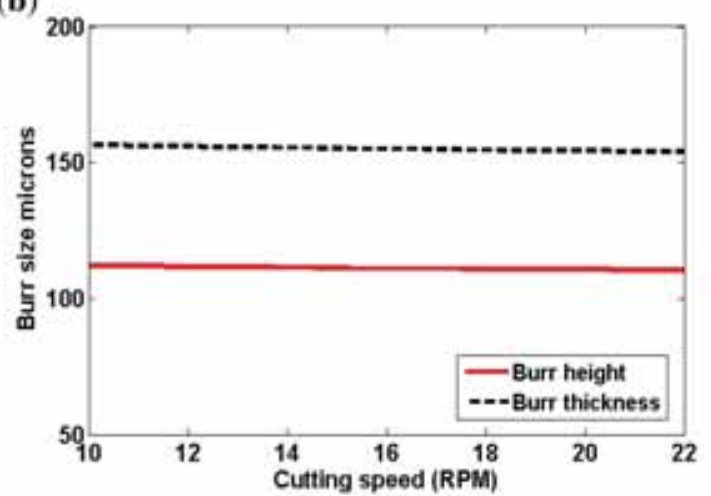

(d)

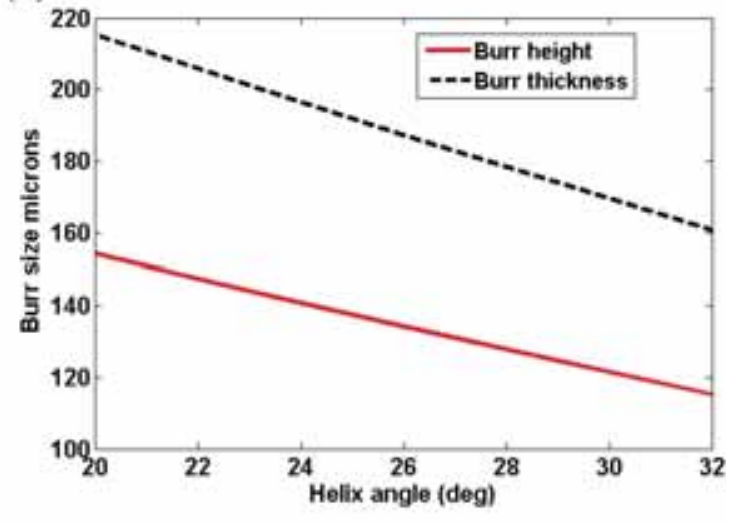

(f)

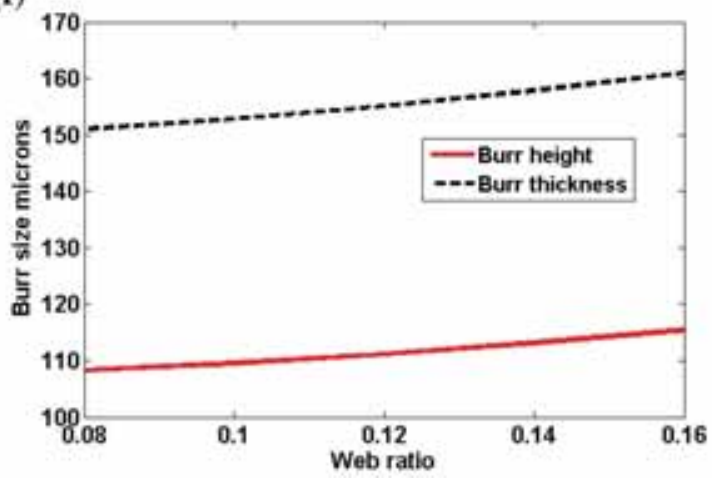

Figure 11. Burr size variation with (a) feed, (b) cutting speed, (c) point angle, (d) helix angle, (e) drill diameter and (f) web ratio.

\section{Model validation}

Drilling experiments were carried out by the authors' group to validate the model. The experiments were divided into two sets. The first set of experiments (Set I) consisted of nine experiments to validate the formation of small drill cap and the thrust forces. The second set of experiments (Set II) consisted of six experiments to validate the temperature and burr size in drilling. In both the experimental sets, the experiments were done on a vertical machining centre (Harding VMC600 II) without any coolant. The parameters used for conducting the experiments for Set I and Set II are given in table 1 . All the experiments were repeated at least twice and measurement of burr characteristics was done a fairly large number of times.

\subsection{Analysis of time variant thrust force data}

A typical thrust force v/s time data is shown in figure 12 . This data is used in the subsequent sections for validating the onset of small drill cap formation and thrust forces by comparing the experimentally determined values with those 
Table 1. Parameters used for conducting experiments in Set I and Set II.

\begin{tabular}{|c|c|c|}
\hline & $\begin{array}{l}\text { Set I (nine } \\
\text { experiments) }\end{array}$ & $\begin{array}{c}\text { Set II (six } \\
\text { experiments) }\end{array}$ \\
\hline $\begin{array}{l}\text { Work material and } \\
\text { size }\end{array}$ & \multicolumn{2}{|c|}{ Grade 5, Ti-6Al-4V $(150 \times 50 \times 8.5 \mathrm{~mm})$} \\
\hline Drill material & \multicolumn{2}{|c|}{ Carbide tipped twist drill } \\
\hline $\begin{array}{l}\text { Chisel edge angle } \\
\text { (deg) }\end{array}$ & \multicolumn{2}{|c|}{$130^{\circ}$} \\
\hline Web ratio & \multicolumn{2}{|c|}{0.13} \\
\hline Helix angle (deg) & \multicolumn{2}{|c|}{$25^{\circ}$} \\
\hline $\begin{array}{l}\text { Drill diameter } \\
\quad(\mathrm{mm})\end{array}$ & $10 \mathrm{~mm}$ & $8.5 \mathrm{~mm}$ \\
\hline Feed $(\mathrm{mm} / \mathrm{rev})$ & $\begin{array}{r}0.05,0.07 \text { and } \\
0.09 \mathrm{~mm} / \mathrm{rev}\end{array}$ & $\begin{array}{c}0.06,0.08 \text { and } \\
0.10 \mathrm{~mm} / \mathrm{rev}\end{array}$ \\
\hline $\begin{array}{l}\text { Cutting speed }(\mathrm{m} / \\
\text { min) }\end{array}$ & $18.84,37.69,47.12$ & 32.04 \\
\hline Point angle (deg) & $140^{\circ}$ & $120^{\circ}$ and $140^{\circ}$ \\
\hline
\end{tabular}

predicted by the model. The machining end time is denoted by $t_{m}$. The time instant at which the thrust forces reduce significantly, that can be attributed to formation of a small drill cap, is denoted as $t_{c}$. It is assumed that after a small drill cap is formed, the thrust forces decrease to a value equal to thrust forces due to the cutting lips only, denoted as $F_{\text {cutting_lips }}$ in figure 12 .

Since it is rather difficult to identify a specific value of the thrust forces and the time instances from the thrust force v/s time data, ranges of thrust forces and time duration have been identified as explained below. The time instant at which a small drill cap is formed, $t_{c}$, is estimated in a window with a lower bound and an upper bound, figure 12 . Similarly, the forces due to the cutting lips are estimated within a lower and an upper bounds. For example, for the thrust force v/s time data shown in figure 12, the time instant at which a crack is initiated, $t_{c}$, is estimated to be $(16 \pm 0.25) \mathrm{s}$ and the force due to the cutting lips is estimated to be around $(400 \pm 40) \mathrm{N}$.

\subsection{Analysis of a small drill cap formation}

The analysis shown here is for the data obtained from three experiments (Set I) conducted at $600 \mathrm{rpm}$ but at different feeds. The analysis for other six experiments can be done in a similar manner. The instant at which a small drill cap is formed is estimated from the thrust forces v/s time plots, figure 13. It may be noted that from the onset of small drill cap formation, till the drilling completes, i.e., from time $t_{c}$ to $t_{m}$, the drill tip moves a distance $h+R / \tan (p)$. This distance can be approximately evaluated from the thrust forces data and is given by,

$$
h+\frac{R}{\tan p}=\left(t_{m}-t_{c}\right) f \frac{N}{60}
$$

The time instant $\left(t_{c}\right)$, with a window of $0.5 \mathrm{~s}$, at which the thrust forces decrease rapidly are noted from the thrust forces $\mathrm{v} / \mathrm{s}$ time data, figure 13. Similarly, the machining end time is estimated with a window of $0.5 \mathrm{~s}$. This data is used to evaluate the distance of the drill tip measured from the bottom surface of the plate, $h$, at which a small drill cap is formed using Eq. (42), and is presented in table 2.

The height of the drill tip at which a fracture is initiated eventually leading to formation of a small drill cap is observed to increase with an increase in feed. Similar trend is predicted by the model. The absolute values differ

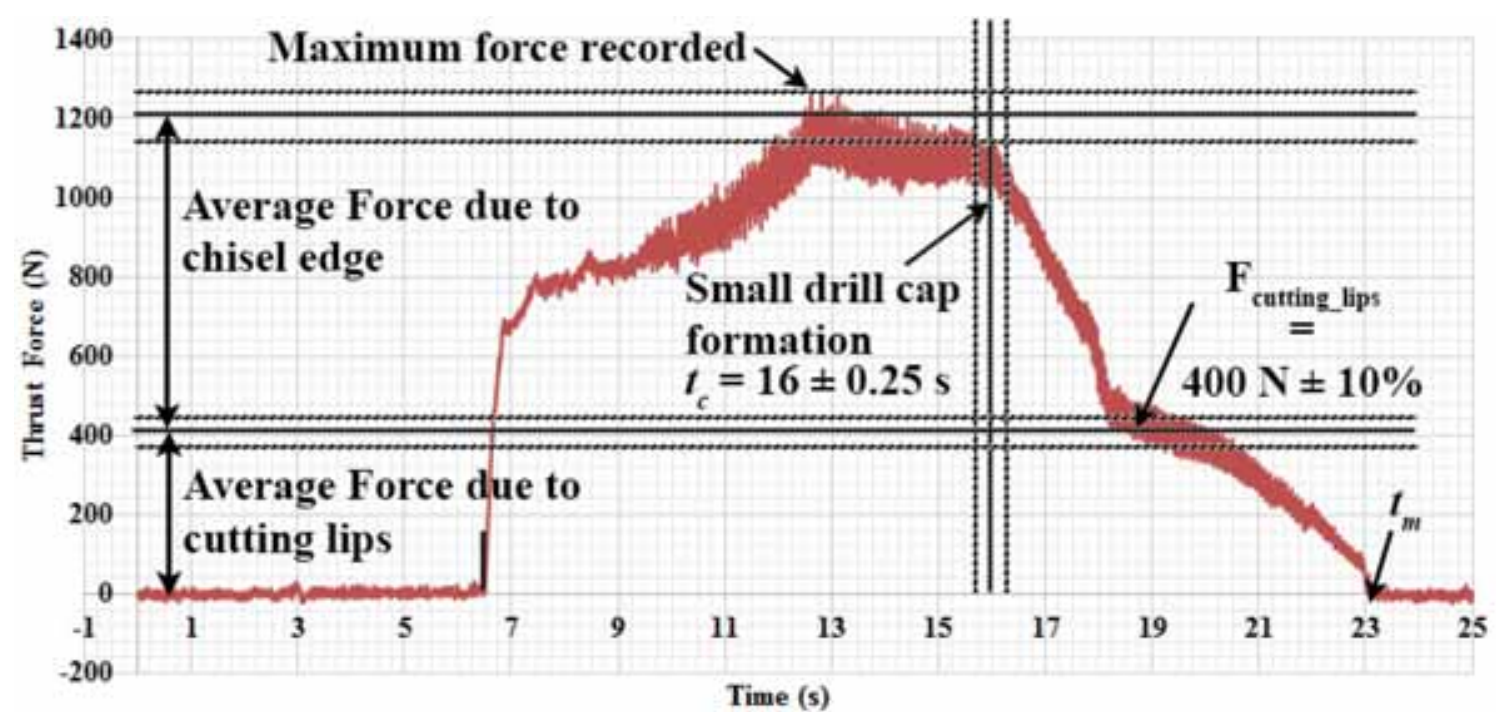

Figure 12. Typical thrust force profile as observed in drilling. 


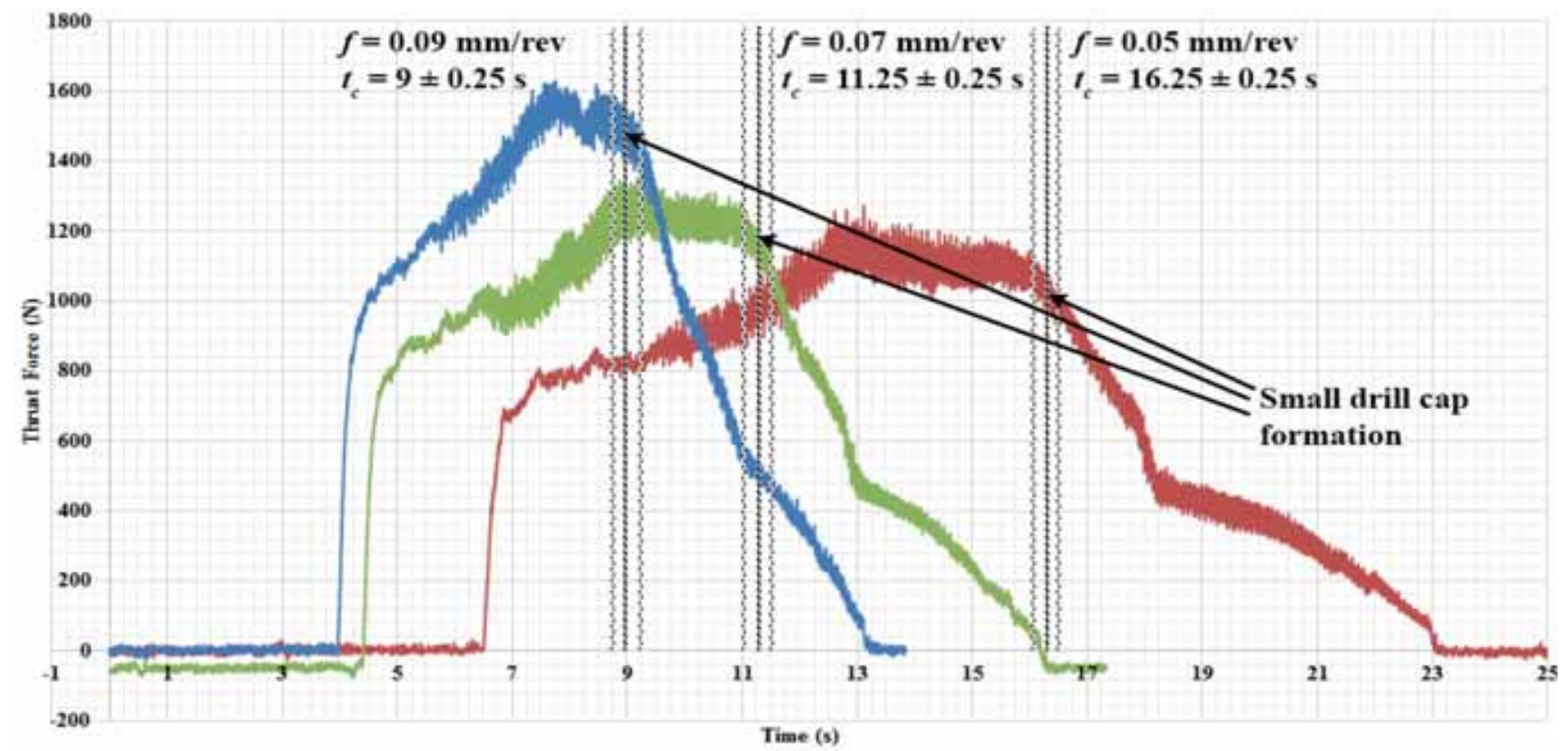

Figure 13. Variation of thrust force with time $(N=600 \mathrm{RPM})$ and formation of small drill cap.

Table 2. Distance of drill tip from bottom surface at which small drill cap is formed.

\begin{tabular}{|c|c|c|c|c|c|c|c|}
\hline \multirow[b]{2}{*}{ Feed } & \multicolumn{2}{|c|}{ Machining end time (s) } & \multicolumn{2}{|c|}{ Time at crack } & \multicolumn{2}{|c|}{ Experimental estimated $h$} & \multirow[b]{2}{*}{$\begin{array}{c}\text { Model } \\
\text { predicted } h\end{array}$} \\
\hline & $\begin{array}{l}\text { Lower } \\
\text { bound } t_{m}^{l}\end{array}$ & $\begin{array}{c}\text { Upper bound } \\
t_{m}^{u}\end{array}$ & $\begin{array}{l}\text { Lower } \\
\text { bound } t_{c}^{l}\end{array}$ & $\begin{array}{c}\text { Upper } \\
\text { bound } t_{c}^{u}\end{array}$ & $\begin{array}{l}\text { Lower bound } \\
\frac{\left(t_{c}^{u}-t_{m}^{l}\right) f N}{60}-\frac{R}{\tan p}\end{array}$ & $\begin{array}{l}\text { Upper bound } \\
\frac{\left(t_{c}^{l}-t_{m}^{u}\right) f N}{60}-\frac{R}{\tan p}\end{array}$ & \\
\hline $\begin{array}{c}(\mathrm{mm} / \\
\mathrm{rev})\end{array}$ & \multicolumn{2}{|c|}{$t_{m}(\mathrm{~s})$} & \multicolumn{2}{|c|}{$t_{c}(\mathrm{~s})$} & \multicolumn{2}{|c|}{$(\mathrm{mm})$} & $(\mathrm{mm})$ \\
\hline 0.05 & 22.75 & 23.25 & 16 & 16.5 & 1.31 & 1.81 & 1.1 \\
\hline 0.07 & 16 & 16.5 & 11 & 11.5 & 1.33 & 2.03 & 1.3 \\
\hline 0.09 & 13 & 13.5 & 8.75 & 9.25 & 1.56 & 2.46 & 1.5 \\
\hline
\end{tabular}

slightly and could be due to the approximate time values as estimated from the visual assessment of the forces data. The bias of the value predicted by the model towards the lower bounds may be due to the assumption of temperature independent stress-strain relation (Eq. (8)) used in plate bending theory.

\subsection{Analysis of burr size}

The burr height at the periphery of the hole was not uniform. Therefore, measurements for burr height were taken at 20 locations along the circumference of the drilled hole. Among these 20 reading, the middle ten values were used to calculate the mean burr height. The mean burr height, along with the error bars of one standard deviation, is plotted with respect to feed and compared with the model predicted burr height for drills having point angles $120^{\circ}$ and $140^{\circ}$, respectively, as shown in figures $3,6,8,14(a)-(b)$.
The predicted burr height is within the error range of the experimentally determined burr height. As expected, the burr height increased with an increase in the point angle of the drill due to large thrust forces associated with drills having large point angles. However, it is observed that the mean burr height (experiment data) first decreases and then increases with an increase in feed. This could be because at low feeds the burr is formed as a result of the tearing action, rather than a cutting and bending mechanism, as described by Saunders and Mauch [16]. The tearing type burr is known to have a larger height as compared to the nontearing burr that is formed by stretching and the bending mechanism.

\subsection{Analysis of thrust forces and temperature profile}

The thrust forces keep varying about a steady-state value. The average steady-stage thrust force is estimated to be 


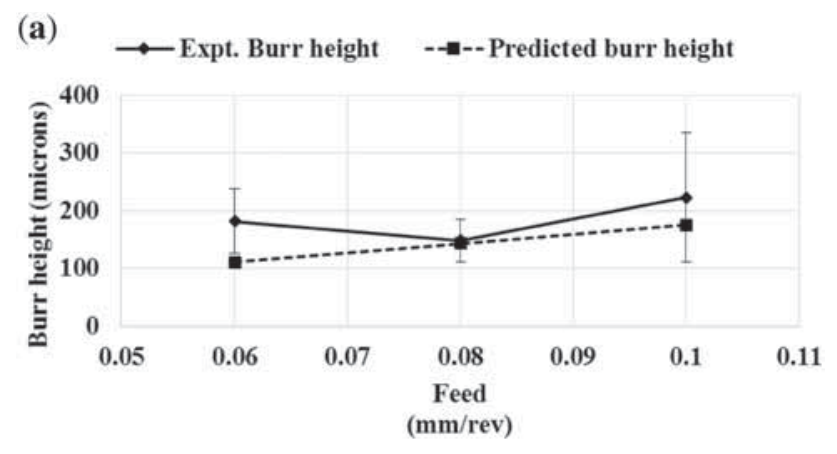

(b)

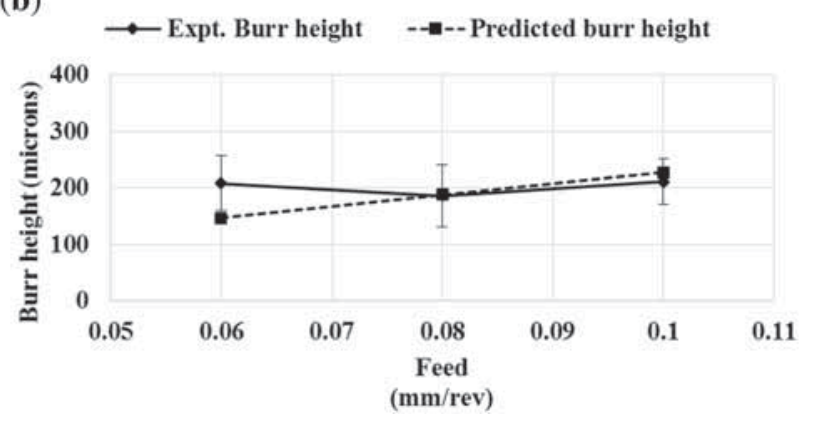

Figure 14. Burr height variation with feed (a) Drill with point angle $120^{\circ}$. (b) Drill with point angle $140^{\circ}$.

0.95 times the maximum thrust force recorded from the thrust force v/s time data. The average error between the total thrust forces evaluated from the experimental data and the model predicted total thrust forces is within $20 \%$, see table 3 .

To validate the temperature, the maximum temperature in drilling below the chisel edge was determined by using a thermal image camera placed below the plate being drilled. A typical image captured using the thermal camera is shown in figure 15. The maximum temperature is near the chisel edge of the drill and the temperature over the cutting lips is nearly identical.

The temperature increases along the chisel edge and is maximum at the chisel edge corner, while a more or less flat temperature profile is observed over the cutting lips.

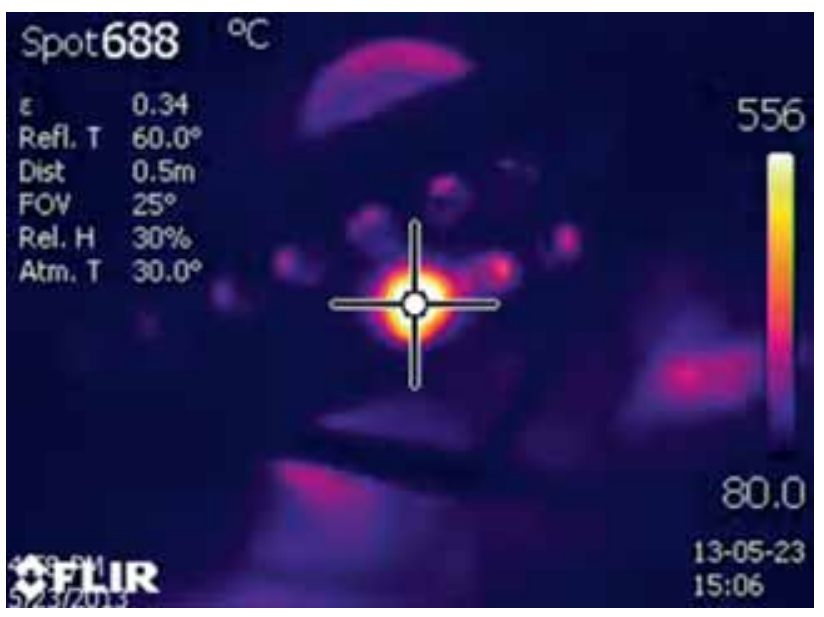

Figure 15. Thermal image showing temperature profile below the chisel edge.

Similar temperature profiles are reported by several researchers include DeVries et al [31] who used embedded thermocouples to measure the temperature, Mills and Mottishaw [32] who investigated the micro-structural changes in the drill material and Bono and $\mathrm{Ni}$ Bono and $\mathrm{Ni}$, $[33,34]$ who measured the temperature in drilling using a drill-foil thermocouple system and observed a nearly flat temperature profile over the cutting lips but higher temperatures near the chisel edge corner.

\section{Conclusions}

- The proposed model of burr formation considers various physical phenomena that occur during the burr formation process, such as the protrusion below the drill tip, initiation of a fracture at the chisel edge corner followed by formation of a small drill cap, and deformation of the material to form a burr. The model also considers the effect of work material property, drill geometry and the processing conditions on the burr formation phenomena. In totality,

Table 3. Comparison of thrust forces determined experimentally with those predicted by the model.

\begin{tabular}{|c|c|c|c|c|c|c|}
\hline $\begin{array}{l}\text { Feed }(\mathrm{mm} / \\
\text { rev) }\end{array}$ & $\begin{array}{l}\text { Cutting speed } \\
\quad(\text { RPM })\end{array}$ & $\begin{array}{c}\text { Experimental max thrust } \\
\text { force }(\mathrm{N})\end{array}$ & $\begin{array}{c}\text { Average steady-state thrust } \\
\text { force }(\mathrm{N})\end{array}$ & $\begin{array}{l}\text { Model predicted thrust } \\
\text { force }(\mathrm{N})\end{array}$ & $\begin{array}{l}\text { Error } \\
(\mathrm{N})\end{array}$ & $\%$ Error \\
\hline 0.05 & 600 & 1273 & 1209 & 1208 & -1 & 0 \\
\hline 0.07 & 600 & 1352 & 1284 & 1471 & 187 & 15 \\
\hline 0.09 & 600 & 1630 & 1549 & 1700 & 151 & 10 \\
\hline 0.05 & 1000 & 1158 & 1101 & 991 & -110 & -10 \\
\hline 0.07 & 1000 & 1311 & 1246 & 1223 & -23 & -2 \\
\hline 0.09 & 1000 & 1562 & 1484 & 1433 & -51 & -3 \\
\hline 0.05 & 1500 & 1073 & 1019 & 828 & -191 & -19 \\
\hline 0.07 & 1500 & 1208 & 1147 & 1042 & -105 & -9 \\
\hline 0.09 & 1500 & 1445 & 1373 & 1245 & -128 & -9 \\
\hline
\end{tabular}


the work presents a complete analytical model of burr formation in drilling considering various physical phenomena.

- The protrusion of the material and formation of a small drill cap is modelled using plate bending theory in conjunction with theory of plasticity. The model uses thrust forces distribution in the chisel edge and cutting lips regions of a drill, and the corresponding drilling temperature while evaluating the bending stresses.

- It is evident from the model that the bending stresses near the chisel edge region are significantly higher as compared to the cutting lips leading to initiation of a fracture at the chisel edge corner. A small drill cap is formed earlier while drilling at higher feeds.

- At higher speeds, the model predicts formation of small drill cap, which is validated using experimental data.

- The model is further extended to predict the burr initiation point at which the material below the drill tip begins to stretch and bend. The burr initiation point is estimated using the principle of energy conservation which is further used to evaluate the final burr size. In this process, the work done to stretch the material contributes to about $70 \%$ of the total work done during exit of drill, while only about $5 \%$ of the total work done is utilised in bending the material. The remaining $25 \%$ of the total work done is by the thrust forces.

- It is observed that the burr size increases with an increase in feed and point angle but decrease with an increase in the helix angle. The burr size increases slightly with an increase in the web ratio. A variation in the cutting speed and the drill diameter does not influence the burr size. The model predicted burr height is observed to be within one standard deviation from the average burr height determined from the experimental dataset.

- The model does not take into consideration ploughing and edge forces. It also ignores a small indentation zone near the chisel edge and friction coefficient variation. The future developments could extend the integration of thrust force and the temperature models done in this work to include the plate bending model.

\begin{tabular}{ll}
\multicolumn{2}{l}{ Nomenclature } \\
$A_{s}$ & shear area \\
$D$ & drill diameter \\
$E$ & second strain invariant \\
$E_{0}$ & maximum permissible strain invariant \\
$f$ & feed per revolution \\
$F_{\text {thrust }}^{\text {chisel }}$ & thrust force due to chisel edge \\
$F_{\text {thrust }}^{\text {cutting }}$ & thrust force due to cutting lips \\
$G$ & shear modulus
\end{tabular}

thickness of circular plate; distance of drill tip measure from bottom surface

burr height

inclination angle

thermal conductivity of tool

thermal conductivity of work-piece

flow stress of work-piece material

tool chip contact length

half-chisel edge length

length of shear zone

radial moment per unit length

circumferential moment per unit length

cutting speed

length of cutting lip

half drill point angle

loading force per unit area

heat flux in shear zone $\left(q_{\text {shear }}^{\prime \prime}=k_{s} V_{s}\right)$

total heat generation flux over tool-chip interface

radial shearing force per unit length

radius of an arbitrary point on the lip or chisel edge from axis of drill

proportion of heat conducted by the chips

time

distance of drill tip measure from bottom

surface at burr initiation point

burr thickness

temperature rise in the shear zone

temperature rise due to friction between chip-

tool interface

specific heat of tool material

specific heat of work-piece material

second stress invariant

tangential speed or cutting speed

velocity of chip

shear velocity

half drill web thickness, width of cut, vertical displacement of circular plate

fraction of friction heat flux acting over the

chip

drill web thickness ratio

thermal diffusivity of tool

thermal diffusivity of work-piece

friction angle, proportion of heat conducted

into work-piece material

normal friction angle

failure strain

radial strain

tangential strain

effective/working rake angle

normal rake angle

half-wedge angle

drill helix angle at the periphery of lips

instantaneous helix angle

chip flow angle 
$\rho_{t} \quad$ density of tool material

$\rho_{w} \quad$ density of work-piece material

$\phi_{n} \quad$ shear angle

$\phi \quad$ angle of the neutral plane

$\varphi \quad$ chisel edge angle

$\sigma_{r} \quad$ radial stress

$\sigma_{\theta} \quad$ circumferential stress

$\bar{\sigma}_{f} \quad$ mean flow stress at bottom surface

\section{Appendix A: Procedure of model evaluation}

In this analysis -

1. The flow stress of the work-piece material is considered to be a function of stress, strain, strain rate and temperature as given by the Johnson-Cook equation below-

$$
k_{s}=\left(A+B \varepsilon^{n}\right)\left(1+C \ln \frac{\dot{\varepsilon}}{\dot{\varepsilon}_{0}}\right)\left[1-\left(\frac{T-T_{\text {room }}}{T_{\text {melt }}-T_{\text {room }}}\right)^{m}\right]
$$

where, $\varepsilon$ is the machining strain (Eq. (33)) and $\dot{\varepsilon} / \dot{\varepsilon}_{0}$ is the ratio of the machining strain rate to a reference strain rate assumed to be in the range of $10^{3}-10^{5}$ Songwon et al [35]. $T, T_{\text {melt }}$ and $T_{\text {room }}$ are the machining temperature, the melting temperature of the work-material and the room temperature, respectively. The constants of the Johnson-Cook equation for Ti6Al4V Songwon et al [35] are $A=997.9 \mathrm{MPa}, \quad B=653.1 \mathrm{MPa}, \quad n=0.45$, $C=0.0198$ and $m=0.7$.

2. The default geometric parameters, cutting conditions used as inputs in the model, unless specified otherwise, are: Diameter $(D)=10 \mathrm{~mm}$, point angle $(p)=120^{\circ}$, web ratio $(2 w / D)=0.13$, chisel edge angle $(\varphi)=132^{\circ}$, feed $(f)=0.1 \mathrm{~mm} / \mathrm{rev}$, cutting speed $(N)=600 \mathrm{rpm}$, chisel edge length $\left(2 L_{c}\right)=\frac{2 w}{\cos \left(\varphi-\frac{\pi}{2}\right)} \approx 1.75 \mathrm{~mm}$.

3. The work-material/tool properties used as inputs are: Specific heat $(\mathrm{J} / \mathrm{kg}-\mathrm{K}) S_{w}=526, S_{t}=517$, thermal conductivity $(\mathrm{W} / \mathrm{m}-\mathrm{K}) K_{w}=6.7, K_{t}=40$, density $\left(\mathrm{kg} / \mathrm{m}^{3}\right)$ $\rho_{w}=4430, \rho_{t}=8000$, work material shear modulus $(\mathrm{GPa})=42$.

4. The Following flow chart gives details of the procedure used in this analysis.

\section{Intermediate variables/values $\quad$ Variables evaluated}

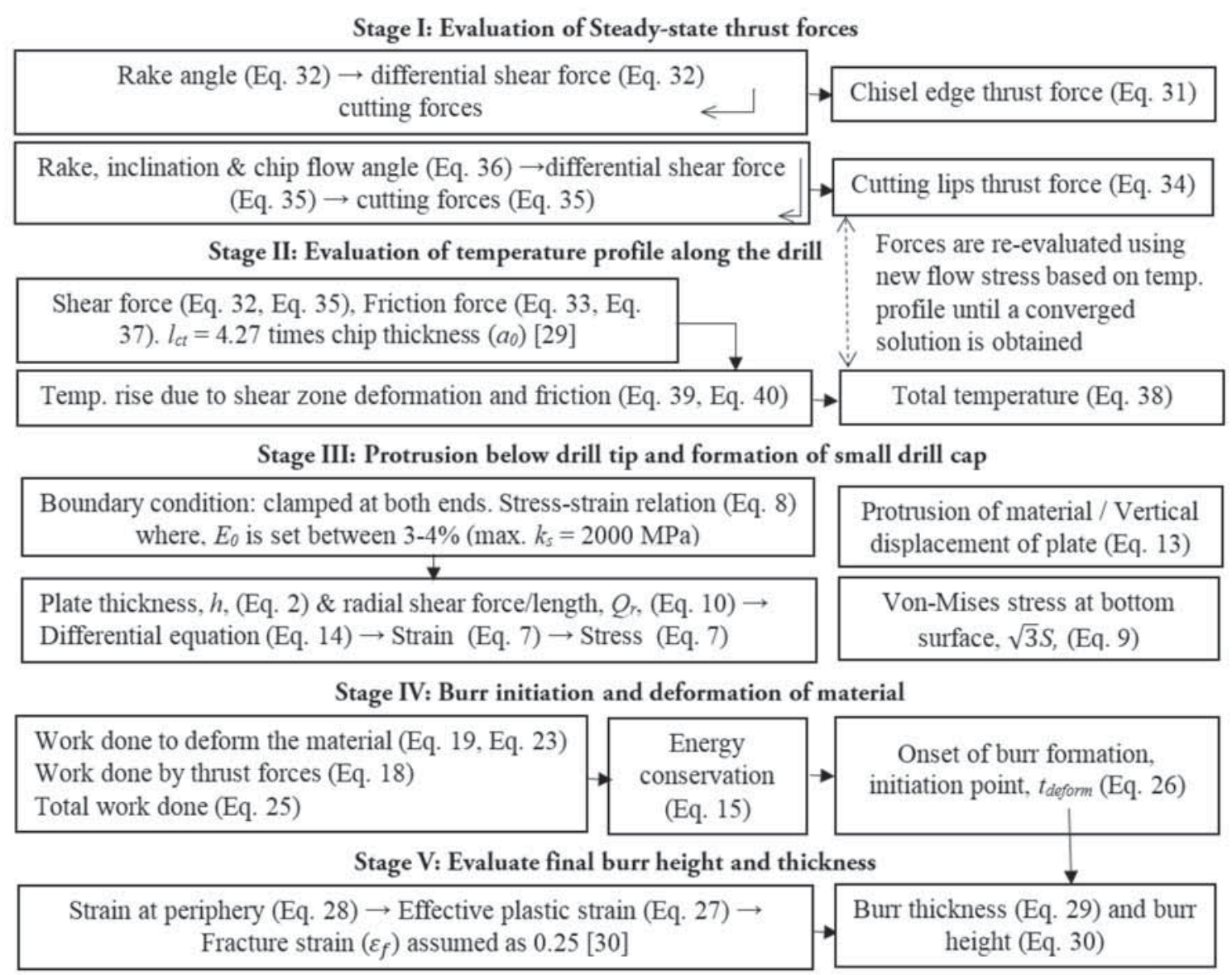




\section{II: Calculation of constants used in equation (26)}

$$
\Delta W_{\text {total }}=\Delta W_{\text {thrustforce }}+\Delta W_{\text {deform }}
$$

$$
\begin{gathered}
\Delta W_{\text {thrust_force }} \\
=\int_{0}^{t_{\text {deform }}+\frac{R}{\tan p}} F_{\text {thrust }}^{\text {cutting lips }}\left[1-\left(\frac{y}{t_{\text {deform }}+\frac{R}{\tan p}}\right)^{1 / 3}\right] d y \\
=\frac{1}{4} F_{\text {thrust }}^{\text {cutting lips }}\left(t_{\text {deform }}+\frac{R}{\tan p}\right) \\
\Delta W_{\text {total }}=F_{\text {thrust }}^{\text {cutting lips }}\left(t_{\text {deform }}+\frac{R}{\tan p}\right) \\
\left.\Delta W_{\text {deform }}=\frac{3 \pi \bar{\sigma}_{f} t_{\text {deform }}\left[\ln \left(\frac{1}{4}\right)+\frac{t_{\text {deform }} \sin ^{2} p \cos p}{R}\right]}{\sin _{p}}\right]+\frac{1}{2} \pi R \bar{\sigma}_{f} t_{\text {deform }}^{2}\left(\frac{\pi}{2}-p\right)
\end{gathered}
$$

The above three equations are mentioned in the paper, from substitution of the above three equations we get the following quadratic equation in $t_{\text {deform }}^{2}$

$$
\begin{gathered}
F_{\text {thrust }}^{\text {cutting lips }}\left(t_{\text {deform }}+\frac{R}{\tan p}\right)=\frac{1}{4} F_{\text {thrust }}^{\text {cutting lips }}\left(t_{\text {deform }}+\frac{R}{\tan p}\right) \\
+\frac{3 \pi \bar{\sigma}_{f} t_{\text {deform }}}{4}\left[\ln \left(\frac{1}{\sin p}\right)+\frac{t_{\text {deform }} \sin ^{2} p \cos p}{R}\right] \\
{\left[R^{2}-L_{c}^{2}\left(2-\frac{L_{c}^{2}}{R^{2}}\right)\right]+\frac{1}{2} \pi R \bar{\sigma}_{f} t_{\text {deform }}^{2}\left(\frac{\pi}{2}-p\right)}
\end{gathered}
$$

On clubbing similar terms we get

$$
\begin{aligned}
& t_{\text {deform }}^{2} \\
& \quad\left[\frac{1}{2} \pi R \bar{\sigma}_{f}\left(\frac{\pi}{2}-p\right)+\frac{3}{4} \pi \bar{\sigma}_{f} \frac{\sin ^{2} p \operatorname{cosp}}{R}\left[R^{2}-L_{c}^{2}\left(2-\frac{L_{c}^{2}}{R^{2}}\right)\right]\right] \\
& \quad+t_{\text {deform }}\left[-\frac{3}{4} F_{\text {thrust }}^{\text {cutting } l i p s}+\frac{3}{4} \pi \bar{\sigma}_{f} \ln \left(\frac{1}{\sin p}\right)\right. \\
& \\
& \left.\left[R^{2}-L_{c}^{2}\left(2-\frac{L_{c}^{2}}{R^{2}}\right)\right]\right]-\frac{3}{4} F_{\text {thrust }}^{\text {cutting lips }}\left(\frac{R}{\tan p}\right)
\end{aligned}
$$

$t_{\text {deform }}=\frac{-b+\sqrt{b^{2}-4 a c}}{2 a}$ is the generic solution of a quadratic equation where a, b, c are the co-efficients of the quadratic equation. Therefore,

$$
\begin{gathered}
a=\frac{1}{2} \pi R \bar{\sigma}_{f}\left(\frac{\pi}{2}-p\right) \\
+\frac{3}{4} \pi \bar{\sigma}_{f} \frac{\sin ^{2} p \operatorname{cosp}}{R}\left[R^{2}-L_{c}^{2}\left(2-\frac{L_{c}^{2}}{R^{2}}\right)\right] \\
b=-\frac{3}{4} F_{\text {thrust }}^{\text {cutting lips }}+\frac{3}{4} \pi \bar{\sigma}_{f} \ln \left(\frac{1}{\sin p}\right)\left[R^{2}-L_{c}^{2}\left(2-\frac{L_{c}^{2}}{R^{2}}\right)\right]
\end{gathered}
$$

and

$$
c=-\frac{3}{4} F_{\text {thrust }}^{\text {cutting lips }}\left(\frac{R}{\tan p}\right)
$$

\section{References}

[1] Gillespie L K 1999 Deburring and Edge Finishing Handbook. New York: Society of Manufacturing Engineers

[2] Ko S L and Lee J K 2001 Analysis of burr formation in drilling with a new concept drill. Journal of Materials Processing Technology 113: 392-398

[3] Sofronas A 1975 The formation and control of drilling burrs. Doctoral dissertation, University of Detroit, Detroit

[4] Jinsoo K and Dornfeld D 2002 Development of an Analytical Model for Drilling Burr Formation in Ductile Materials. ASME Transactions Journal Engineering Materials and Technology 124: 192-198

[5] Ravi L, Bajpai V, Singh R K and Joshi S S 2011 Characterization and modeling of burr formation in micro-end milling. Precision Engineering 35: 625-637

[6] Niknam S A and Songmene V 2013 Modelling of burr thickness in milling of ductile materials. International Journal of Advanced Manufacturing Technology 66: 2029-2039

[7] Deng W J, Xia W and Tang Y 2009 Finite element simulation for burr formation near the exit of orthogonal cutting. International Journal of Advanced Manufacturing Technology 43:1035-1045

[8] Matsumura T and Leopold J 2010 Simulation of Drilling Process for Control of Burr Formation. Journal of Advanced Mechanical Design, Systems and Manufacturing 4: 966-975

[9] Chang S S and Bone G M 2010 Burr height model for vibration assisted drilling of aluminum 6061-T6. Precision Engineering 34:369-375

[10] Stéphane S, Masounave J and Songme V 2013 A simple analytical model for burr type prediction in drilling of ductile materials. Journal of Materials Processing Technology 213: 971-977

[11] Saunders L K Land Mauch C A 2001 An exit burr model for drilling of metals. Transactions of the ASME 123: 562-566

[12] Lauderbaugh L K 2009 Analysis of the effects of process parameters on exit burrs in drilling using a combined simulation and experimental approach. Journal of Materials Processing Technology 2009: 1909-1919

[13] Abdelhafeez A M, Soo S L, Aspinwall D K, Dowson A and Arnold D 2015 Burr formation and hole quality when drilling titanium and aluminum alloys. Procedia CIRP 37: 230-235

[14] Mondal N, Sardar B S, Halder R N and Das S 2014 Observation of drilling burr and finding out the condition for minimum burr formation. International Journal of Manufacturing Engineering 208293

[15] Rezende B A, Silveira M L, Vieira L M, Abrão A M, Faria P E and Rubio J C 2016 Investigation on the effect of drill geometry and pilot holes on thrust force and burr height when drilling an aluminium/PE sandwich material. Materials 9: 774

[16] Deger B, Melemez F F and Ing A K 2016 Effect of cutting parameters on dimensional hole quality and burr height for one-shot drilling of hybrid stacks. SAE Technical Paper 2016

[17] Kundu S, Das S and Saha PP 2016 Effect of exit edge beveling on burr height in drilling aluminium alloy. In: 
Proceedings of 6th International \& 27th All India Manufacturing Technology, Design and Research Conference, Pune, Maharashtra, India, December 16-18, 2016

[18] Sekulić M, Kovač P, Gostimirović M, Jurković Z and Savković B 2010 A new thrust force model for drilling process. Journal of Production Engineering 13: 19-22

[19] Singh A P and Sharma M 2013 Modelling of thrust force during drilling of fibre reinforced plastic composites. Procedia Engineering 51: 630-636

[20] Chakrabarty J 2009 Plastic bending of plates. Applied Plasticity, New York: Springer, 227-248

[21] Merckx K R 1953 Plastic bending of circular plates symmetrically loaded Stanford, California

[22] Furness R 1998 High Speed Video of Drilling Burr Formation. AMTD, Ford Motor Company

[23] Rana A 2014 Modelling mechanics of burr formation to predict exit burr size in drilling Ti6Al4V M. Tech Thesis. IIT Bombay Mumbai, India

[24] Makhecha A, Thangaraj A R and Sutherland J W 1994 Prediction of drilling thrust and torque using a mechanistic model calibrated through non-linear optimization. Manufacturing Science and Engineering ASME 68: 237-244

[25] Bono M J and Jun Ni 2001 The indentation zone of a twist drill. Transactions of the North American Manufacturing Research Institute of SME. New York: Society of Manufacturing Engineers

[26] Merchant M E 1945 Basic mechanisms of the metal cutting process. Journal of Applied Physics 16: 267-275
[27] Groover M P 2010 Fundamentals of Modern Manufacturing: Materials, Processes, and Systems. 4th ed., New York: John Wiley and Sons

[28] Oxley P LB 1989 Mechanics of Machining an Analytical Approach to Assessing Machinability. Chichester: Ellis Horwood Limited

[29] Li R and Shih A J 2007 Tool temperature in titanium drilling. Transactions of the ASME 129: 740-749

[30] Agapiou J S and DeVries M F 1990 On the determination of thermal phenomena during drilling-Part I. Analytical models of twist drill temperature distributions Int. J. Mach. Tools Manuf. 30: 203-215

[31] DeVries M F, Saxena U K and Wu S M 1968 Temperature distributions in drilling. Journal of Engineering for Industry 90: $231-238$

[32] Mills B and Mottishaw T.D1981 The application of scanning electron microscopy to the study of temperatures and temperature distributions in M2 high speed steel twist drills. Annals of the CIRP 30: 15-20

[33] Bono M and Ni J 2002 A method for measuring the temperature distribution along the cutting edges of a drill. Journal of Manufacturing Science and Engineering 124: 921-926

[34] Jian W U and Rong-di H 2012 Friction characteristics in green drilling titanium alloy Ti6Al4V. Journal of Shanghai Jiaotong University (Science) 17: 684-689

[35] Songwon S, Oakkey M and Hyunmo Y 2005 Constitutive equation for Ti-6Al-4V at high temperatures measured using the SHPB technique. International Journal of Impact Engineering 31: 735-754 